\title{
JUSTICE, CLAIMS AND PRIORITARIANISM: ROOM FOR DESERT?
}

\author{
Matthew D. Adler, Duke University, adler@law.duke.edu. ${ }^{1}$ Draft of October 24, 2016.
}

\section{Introduction}

Distributive justice respects the separateness of persons. This is hard to dispute and indeed, since Rawls, has been a truism in the philosophical literature about distributive justice.

In my prior work, I have used the concept of "across-outcome claims" to specify the content of distributive justice, consistent with justice's grounding in the separateness of persons. ${ }^{2}$ An across-outcome claim (for short, "claim") is a three-part relation between a person and two outcomes. Moreover, claims are "valenced" by well-being. That is to say: a person has a claim in favor of one outcome over a second just in case she is better off in the first outcome; and she has a null claim between the outcomes just in case she is equally well off in the two.

This construal of claims - as having an across-outcome structure, valenced by wellbeing-builds upon seminal insights of Thomas Nagel in his 1977 Tanner Lecture and his book Equality and Partiality. ${ }^{3}$

My prior work on the claims framework assumes undifferentiated desert. Individuals are equally situated with respect to all non-well-being characteristics — whatever these might bethat plausibly could be thought to bear upon the strength of individual claims. In the case of undifferentiated desert, the claims framework argues for three fundamental clusters of principles: first, the two well-being Pareto principles (Pareto indifference and strong Pareto); second, the Pigou-Dalton principle; and finally, the Anonymity principle. A ranking of outcomes that satisfies these principles is not, yet, a prioritarian ranking. ${ }^{4}$ However, by adding additional axioms to the mix, we arrive at prioritarianism and (yet more specifically) at continuous prioritarianism.

It is natural to think that the claims framework should be generalized to allow for desertmodulated claims. In this, more general, case the strength of an individual's claim between two outcomes depends not merely upon her well-being level in the two outcomes, and her well-being difference between them, but also her desert level (in some sense)—or so the thought goes.

\footnotetext{
${ }^{1}$ Many thanks for comments to Richard Arneson, Luc Bovens, Vincent Conitzer, Richard Fallon, Jimmy Goodrich, Jerry Green, Till Grüne-Yanoff, Frances Kamm, Marcus Pivato, Wlodek Rabinowicz, Caleb South, Larry Temkin, and Alex Voorhoeve, and to workshop participants at Duke, Harvard, LSE, Lund, Oxford, Rutgers, Stockholm and UNC. All errors are my own.

${ }^{2}$ Matthew D. Adler, Well-Being and Fair Distribution: Beyond Cost-Benefit Analysis (New York: Oxford University Press, 2012), ch. 5.

3 "Equality," in Mortal Questions (Cambridge: Cambridge University Press, 1979), 106-127; Equality and Partiality (New York: Oxford University Press, 1995).

${ }^{4}$ See below, Part III.
} 
Desert in this context might be understood as degree of prudence. An individual who has failed to attend to her own interests, frittering away her resources or deploying them recklessly, has a weaker claim to be brought up from a low level of well-being than the prudent person who finds herself at the very same level of well-being because of bad luck. Alternatively, desert might be understood as moral conscientiousness. Ceteris paribus, someone who has tried hard to do what is morally right (as a matter of justice, or as a matter of morality all-thing-considered) has a stronger claim than someone who has selfishly ignored the interests of others. ${ }^{5}$

The thought that individual claims should take account of both well-being and desert is bolstered by Richard Arneson's work on desert-adjusted prioritarianism. Arneson, a pioneer on the topic of luck egalitarianism, has shifted from egalitarianism to prioritarianism. ${ }^{6}$ Further, Arneson proposes a version of prioritarianism that, in allocating benefits, not only gives priority to those who are worse off (as does standard prioritarianism), but also takes account of individuals' desert levels.

The picture then is that increasing human well-being and preventing reductions of it is always morally a good thing, but the moral goal is not to maximize the sum total of well-being but to maximize the total of well-being weighted by distributional factors. One factor is priority [for those at lower well-being levels]. A second is that it is better to obtain a gain for a person who is specifically more deserving than others to whom the same-sized gain might be given. One is specifically more deserving than others who might be accorded the benefit in question if channeling the benefit to one rather than to any of the others would do most to bring it about that the well-being levels these people are at are proportional to their level of desert. Other things being equal, it is better to get a benefit to someone who is more deserving in this sense, and, other things being equal, it is better to get a benefit to someone, the lower her lifetime well-being without this benefit .... ${ }^{7}$

In short, "[t]he position we then arrive at is desert and well-being prioritarianism with extra priority to well-being gains for the comparatively more deserving." 8

It is clear from other portions of Arneson's text that he proposes desert-adjusted prioritarianism as a conception of justice. Both a person's level of well-being, and her degree of desert, determine whether it would be more just (not merely morally better in some non-justice sense) to benefit her rather than another. Arneson writes: "Distributive justice can be regarded as setting criteria that establish queues of persons standing in line to receive various benefits that

\footnotetext{
${ }^{5}$ On the various plausible conceptions of desert for purposes of desert-modulated claims, see below, Part IV.

${ }^{6}$ Arneson's early and influential work on luck egalitarianism includes "Equality and Equal Opportunity for Welfare," Philosophical Studies 56 (1989): 77-93; and "Liberalism, Distributive Subjectivism, and Equal Opportunity for Welfare," Philosophy and Public Affairs 19 (1990): 158-94. He subsequently endorsed prioritarianism in a series of articles, including: "Debate: Equality of Opportunity for Welfare Defended and Recanted," The Journal of Political Philosophy 7 (1999): 488-97; "Egalitarianism and Responsibility," The Journal of Ethics 3 (1999): 225-47; "Luck Egalitarianism and Prioritarianism," Ethics 110 (2000); 339-49; and "Desert and Equality," in Egalitarianism: New Essays on the Nature and Value of Equality, ed. Nils Holtug and Kasper LippertRasmussen (Oxford: Clarendon Press, 2007), 262-93.

${ }^{7}$ Arneson, "Desert and Equality," 283.

${ }^{8}$ Ibid., 287
} 
are in the offing. Comparative desert and prior well-being level affect one's place in the queue ,9

This Article looks carefully at the concept of desert-modulated claims: at the idea that someone's "place in the queue," the relative strength of her claim to a benefit as a matter of justice, depends upon both her well-being level and her desert. ${ }^{10}$

My conclusion, alas, is negative. Desert-modulated claims conflict with Pareto indifference. Moreover, if we add a continuity axiom, desert-modulated claims also conflict with strong Pareto. If the continuity axiom is dropped, desert-modulated claims are consistent with strong Pareto- but only if desert is limited to a minimal, tiebreaker role in determining the strength of individual claims.

A fair bit of argumentation will be required to support my conclusion that the project of desert-modulated claims is untenable. I will need not only to clarify the conflict between such claims and the Pareto principles - a conflict that arises when desert is intrapersonally variable rather than fixed between the alternatives under consideration — but also, more fundamentally, to support the assertion that the Pareto principles are principles of justice. The more widespread view is otherwise: that the Pareto principles flow from non-justice considerations, such as overall well-being or efficiency.

My prior elaboration of the claims framework worked within a consequentialist view of morality and justice; but the concept of across-outcome claims can be generalized beyond consequentialism, and I do so here. The tension between desert and claims is orthogonal to the debate between consequentialists and non-consequentialists.

The Article is divided into six parts. Part I sets forth some basic presuppositions about justice. Part II defends the "Generalized Pareto principles" as principles of justice. These become, more specifically, the well-being Pareto principles if well-being is taken as the "currency" of justice. Part III summarizes the claims framework with undifferentiated desert.

\footnotetext{
${ }^{9}$ Ibid., 283.

${ }^{10}$ For prior work on the relation between desert and distributive justice, see, in addition to Arneson: Fred Feldman, Utilitarianism, Hedonism and Desert (Cambridge: Cambridge University Press, 1997); Serena Olsaretti, ed., Desert and Justice (Oxford: Oxford University Press, 2003); sources cited in Serena Olsaretti, "Introduction: Debating Desert and Justice," in Desert and Justice, 1-24, at 1-2; Matthew Rendall, "Priority and Desert," Ethical Theory and Moral Practice 16 (2013): 939-51; Carl Knight, "Responsibility, Desert and Justice," in Responsibility and Distributive Justice, ed. Carl Knight and Zofia Stemplowska (Oxford: Oxford University Press, 2011), 152-73; Larry Temkin, “Justice, Equality, Fairness, Desert, Rights, Free Will, Responsibility, and Luck," in Responsibility and Distributive Justice, 51-76; Gustaf Arrhenius, "Desert as Fit," in The Good, the Right, Life and Death, ed. Richard Feldman et al (Burlington: Ashgate, 2006), 3-18; John Roemer and Alain Trannoy, "Equality of Opportunity," in Handbook of Income Distribution, ed. Anthony Atkinson and Francois Bourguignon (Amsterdam: Elsevier, 2015), vol. 2A, 217-300, at 233-34.
} 
Parts IV and V consider the claims framework with desert-modulated claims. In this case, four fundamental clusters of principles seem very plausible: first, the two well-being Pareto principles (indifference and strong); second, a modified version of the Pigou-Dalton principle; third, a modified version of the Anonymity principle; and, finally, a new principle, Priority for the More Deserving, which says this: as between two individuals at the same well-being level, a given well-being benefit should be conferred upon the more deserving one.

In the case of intrapersonally fixed desert, the four clusters of principles are consistent. Adding further axioms, we arrive at desert-modulated continuous prioritarianism. However, if the set of alternatives being considered is such that a given individual's desert level can vary between alternatives, Priority for the More Deserving may come into conflict with the Pareto principles.

Part VI considers various strategies for rescuing the project of desert-sensitive claims, given the conflict outlined in Part V. It concludes that none suffice to do so.

The motivating concern of the literature on luck egalitarianism is that the pattern of distribution of well-being, without more, seems insufficient to determine the justice of that distribution. Further factors, such as individual control, choice, responsibility or desert also seem to be relevant. ${ }^{11}$ Does the Article show that this motivating concern is incompatible with the claims framework? No: what it shows is that the integration of that concern with this framework cannot be achieved via the desert channel: by making someone's desert a determinant of what she can justly claim. The broader question of luck egalitarianism and claims cannot be discussed at length here, but is briefly addressed in the Article's conclusion.

\section{Justice: Some Presuppositions}

Consequentialists believe that outcomes (whole possible worlds or cognitively tractable models thereof) are the fundamental items of moral assessment. Thus justice, in particular, takes the form of ranking outcomes. If the idea of a "claim" is indeed useful in fleshing out the content of justice, then this will be a claim formulated in terms of outcomes-for example, a claim across outcomes. ${ }^{12}$

However, the topic of this Article - the relation between desert, justice and claimstranscends consequentialism, and so for purposes of what follows I leave aside debates about consequentialism. Rather than supposing that justice ranks outcomes, I assume (more generally) that it takes the form of ranking "alternatives" - a shorthand for the fundamental items of justice assessment, whatever they may be. If $x, y, z$, etc. are alternatives, and $\mathbf{S}=\{x, y, z, \ldots\}$ is a set of

\footnotetext{
${ }^{11}$ For overviews of this large literature, see Carl Knight, Luck Egalitarianism: Equality, Responsibility and Justice (Edinburgh: Edinburgh University Press, 2009); Kasper Lippert-Rasmussen, Luck Egalitarianism (London:

Bloomsbury Academic, 2016); Shlomi Segall, Why Inequality Matters: Luck Egalitarianism, Its Meaning and Value (Cambridge: Cambridge University Press, 2016).

${ }^{12}$ Adler, Well-Being and Fair Distribution, ch. 5.
} 
such alternatives, the set $\mathbf{S}$ will be ranked as a matter of justice. Items that are not alternatives may also be evaluable by justice; but if so such evaluations are derived from the justice ranking of alternatives. ${ }^{13}$ Alternatives could be outcomes (so say consequentialists), but they could also be institutions; actions; distributions of physical resources; or something else.

I assume that justice is grounded in the separateness of persons. It is indeed a truism that distributive justice is grounded in the separateness of persons, but not that corrective or retributive justice is. By "justice," then, I mean distributive justice together with any other components of morality that are grounded in the separateness of persons. This usage of "justice" is a term of art, since it may exclude corrective and/or retributive justice. Nor, to be clear, am I presupposing that all of morality is grounded in the separateness of persons.

In what sense is the justice ranking of a set of alternatives "grounded in the separateness of persons"? What such grounding means will be fleshed out as the analysis proceeds, but to begin we can say this: how alternatives compare with respect to justice is determined by the totality of facts about how they compare from the perspective of each person. A bit more precisely: there is a (fixed and finite) population of concern (individual 1 , individual $2, \ldots$, individual $N$ ); for each person in the population, and any set $\mathbf{S}$ of alternatives, the set can be ranked from the perspective of that person; and the justice ranking of $\mathbf{S}$ supervenes upon the collection of these rankings.

For short, I'll refer to the ranking of $\mathbf{S}$ from the perspective of one or another person as a "person-centered ranking" or use cognate terms such as "person-centered comparison" or "comparison from the standpoint of a person." To avoid any ambiguity, we might instead call this a "person-centered ranking for purposes of justice," namely, the specific kind of personcentered ranking that constitutes the supervenience base for justice. But this longer terminology is unnecessarily clunky, here, since our interest throughout is justice.

A final assumption is that the justice ranking is "well-behaved" in the sense of being a quasiordering: a transitive, reflexive, binary relation. That is: (1) for any two alternatives $x$ and $y$, either $x$ is at least as just as $y$, or $y$ is at least as just as $x$, or both, or the two alternatives are noncomparable; and (2) if $x$ is at least as just as $y$, and $y$ is at least as just as $z$, then $x$ is at least as just as $z \cdot{ }^{14}$

The quasiordering assumption is not a trivial one. Transitivity is central to the arguments below against desert-sensitive claims; further, transitivity has recently been challenged in the

\footnotetext{
${ }^{13}$ For example, if the fundamental items of justice assessment are outcomes, the ranking of other items should satisfy a suitable dominance axiom in terms of outcomes (such as stochastic dominance, if non-fundamental items are understood as probability distributions across outcomes). See Adler, Well-Being and Fair Distribution, ch. 7. These issues need not be further pursued here.

${ }^{14}$ The relations of "more just than" and "equally just as" are in turn derivable from the "at least as just" relation (in the standard manner for a quasiordering). $x$ is more just than $y$ iff $x$ is at least as just as $y$ but $y$ is not as least as just as $x$. $x$ and $y$ are equally just iff $x$ is at least as just as $y$ and $y$ is at least as just as $x$.
} 
philosophical literature. ${ }^{15}$ However, like many others, I find transitivity to be a compelling axiom, and will take it as given.

Putting this all together: "Justice" takes the form of a ranking of alternatives; this ranking is formally well-behaved in the sense of being a quasiordering; and it is grounded in the separateness of persons in the sense that whether $x$ is at least as just as $y$ depends upon how the alternatives compare from the perspective of each person in the population, i.e., how $x$ and $y$ are ranked by each individual's person-centered ranking.

\section{The Generalized Pareto Principles}

The hotly debated question of the "currency" of justice now comes into view. A variety of "currencies" have been suggested, including: well-being; resources; "advantage," a mix of resources and well-being; the degree to which individuals' all-things-considered preferences are satisfied; or capabilities. ${ }^{16}$ This debate has been undertaken under the rubric of the question, "Equality of What?" Insofar as justice is (non-instrumentally) promoted by the equalization of some distribuendum — some currency — which item is that?

But I think it's inadequate merely to see a candidate currency as a candidate answer to the question, "Equality of What?" If justice is grounded in the separateness of persons, then equalizing the distribution of some currency non-instrumentally promotes justice only if doing so is, on balance, recommended by the totality of individual perspectives. ${ }^{17}$ And that, in turn, will be true only if increasing a given person's holdings of the currency is, necessarily, an improvement in light of her person-centered ranking.

In short, as I see it, the question of currency is nothing other than the question of how comparisons are to be made from the standpoint of each person for purposes of determining what justice requires. Identifying a currency means specifying what these person-centered comparisons consist in. If welfare is the currency for justice, then: alternative $x$ is at least as highly ranked as alternative $y$ in individual $i$ 's person-centered ranking iff individual $i$ 's level of well-being with alternative $x$ is at least as great as her level of well-being with alternative $y$. If resources are the currency for justice, then: $x$ is at least as highly ranked as $y$ in individual $i$ 's person-centered ranking iff individual's $i$ 's resource holdings with $x$ are at least as large (by

\footnotetext{
${ }^{15}$ Larry S. Temkin, Rethinking the Good: Moral Ideals and the Nature of Practical Reasoning (Oxford: Oxford University Press, 2012).

${ }^{16}$ See Ronald Dworkin, "What is Equality? Part 2: Equality of Resources," Philosophy and Public Affairs 10 (1981): 283-345 (resources); Richard J. Arneson, "Welfare Should be the Currency of Justice," Canadian Journal of Philosophy 30 (2000): 497-524 (welfare); G.A. Cohen, “On the Currency of Egalitarian Justice,” Ethics 99 (1989): 906-44 (advantage); Lippert-Rasmussen, Luck Egalitarianism, at 98-101 ("non-instrumental concern," i.e., allthings-considered intrinsic preferences, including non-self-regarding preferences); Amartya Sen, Inequality Reexamined (New York: Russell Sage, 1992) (capabilities). For an overview of the debate about currency, see Lippert-Rasmussen, Luck Egalitarianism, 77-112.

${ }^{17}$ Conversely, if $C$ is the currency, and the Pigou-Dalton principle with respect to $C$ captures what is most just on balance, from the totality of individual perspectives, equalizing $C$ non-instrumentally promotes justice. The PigouDalton principle is defended below.
} 
some criterion for assessing the size of resource holdings) as $i$ 's resource holdings with $y$. If allthings-considered preferences are the currency for justice, then: $x$ is at least as highly ranked as $y$ in individual $i$ 's person-centered ranking iff individual $i$ 's all-things-considered preferences are such as to weakly prefer $x$ to $y$.

I find the welfare currency very plausible. ${ }^{18}$ Still, plausible arguments can be made in favor of each currency just mentioned, not just welfare; this is indeed why the debate about currency has occurred.

Consider, now, the "generic Pareto principles," as follows. These are "generic" just in the sense of leaving open the question of currency. (a) Generic Pareto Indifference. If alternatives $x$ and $y$ are ranked as equal from the standpoint of each person, then $x$ and $y$ are equally just. (b) Generic Strong Pareto. If $x$ is more highly ranked than $y$ from the standpoint of at least one person, and at least as highly ranked from each person's standpoint, then $x$ is more just than $y$.

To understand what these mean, consider (for example) that Generic Pareto Indifference, combined with the view that the currency of justice is all-things-considered preferences, yields a more specific Pareto-indifference principle which says: If each person is indifferent (all things considered) between two alternatives, the two are equally just. Combined, instead, with a resourcist view of the currency of justice, we have a different, more specific Pareto-indifference principle which says: if each person has the same amount of resource holdings with alternative $x$ as she does with alternative $y$, the two alternatives are equally just. Combined with a simple welfarist view of justice's currency, we have that: if each person's level of well-being with alternative $x$ is the same as her level of well-being with alternative $y$, the two alternatives are equally just. Similar substitutions hold for Generic Strong Pareto.

Although the various specifications of the generic Pareto principles, inserting one or another candidate currency, will certainly be controversial-because the nature of the currency is - the generic principles themselves seem compelling. If the justice ranking of alternatives is

\footnotetext{
${ }^{18}$ Why? To begin, "well-being" has intrinsic value. The flourishing of someone's life is a kind of intrinsic goodness. It is fully rational (in the sense of being intelligible and reasonable, not merely formally rational) for some actor to take as her aim the promotion of some beneficiary's well-being - whether her own well-being, or the well-being of someone else she cares about. By contrast, there is no intrinsic value in the other candidates for justice's currency.

Further, well-being is not merely an intrinsic value, but exactly the sort of intrinsic value to be such that comparisons from each given person's standpoint for purposes of justice track this value. Well-being is personcentered value. We differentiate between the well-being of one person and the well-being of someone else. Sue's well-being is Sue's because grounded, in a complicated way (itself a matter of dispute among welfarists) in Sue's mental states, physical states, preferences, and other features of Sue's life. Thus the truism that "well-being" is goodness for - value relativized to one or another person. The comparison of alternatives with respect to Sue's well-being is a value comparison, and indeed a comparison with respect to what is valuable for Sue.
} 
indeed grounded in the separateness of persons - built up from the plurality of standpoints of all the persons in the population of concern - then surely if every standpoint sees the choice between two alternatives as a matter of indifference, the two must be equally just. In such a case, only an impersonal consideration (something above and beyond how the alternatives compare from everyone's standpoints) could make it the case that one alternative is affirmatively more just than the second. As for Generic Strong Pareto, consider that, if the ranking of alternatives is grounded in the separateness of persons, then: (a) the fact that alternative $x$ is ranked higher than alternative $y$ from someone's standpoint should surely have pro tanto weight in favor of $x$, and moreover (b) only other personal considerations, i.e., the fact that $x$ is ranked lower than $y$ from someone else's standpoint, should be able to override this pro tanto weight.

The position I have just argued for-that the generic Pareto principles are core principles of justice-is novel in several ways. First, philosophers often use the term "Pareto" to mean what John Broome terms the "principle of personal good,"19 namely the well-being Pareto principles ${ }^{20}$ while economists almost invariably focus on the Pareto principles in terms of preferences. $^{21}$ By articulating and defending the generic Pareto principles, I am trying to forestall the challenges to specific variants thereof that will arise from disputation about the role in distributive justice of individual welfare, preferences, resource holdings, or other specific proposals for how the personal perspective undergirds justice. In virtue of such disputation, the well-being Pareto principles, the preference Pareto principles, the resources Pareto principles, etc., will inevitably be controversial; but by laying out the common structural feature of these various specific axioms, as per the generic Pareto principles, we can see (I suggest) why the Pareto principles in some form have seemed so appealing to many.

Second, philosophical debate rarely sees the Pareto principles as principles of justice. ${ }^{22}$ Third, and relatedly, those who endorse the Pareto principles often do so as axioms governing the moral ranking of alternatives - that is, the ranking of alternatives in light of the totality of moral considerations, given all the components of morality - rather than as axioms for the justice ranking. ${ }^{23}$

\footnotetext{
${ }^{19}$ Weighing Goods: Equality, Uncertainty, and Time (Oxford: Blackwell, 1991).

${ }^{20}$ See, e.g., Michael Huemer, "Against Equality and Priority," 24 Utilitas (2012): 483-501; Campbell Brown, "Consequentialize This," Ethics 112 (2011): 749-71; Thomas Porter, "Prioritarianism and the Levelling Down Objection," Ethical Theory and Moral Practice 14 (2011): 197-206; Bertil Tungodden and Peter Vallentyne, "On the Possibility of Paretian Egalitarianism," Journal of Philosophy 102 (2005): 126-49; Nils Holtug, "Welfarism: The Very Idea," Utilitas 15 (2003): 151-74.

${ }^{21}$ See, e.g., Andreu Mas-Collel, Michael D. Whinston and Jerry Green, Microeconomic Theory (New York: Oxford University Press, 1995), 825.

${ }^{22}$ See, e.g., G.A. Cohen, Rescuing Justice and Equality (Cambridge: Harvard University Press, 2008), 315; Larry Temkin, "Equality, Priority and the Levelling Down Objection," in The Ideal of Equality, ed. Matthew Clayton and Andrew Williams (Houndmills: Palgrave, 2000), 122-26. But see Nils Holtug, Persons, Interests, and Justice (Oxford: Oxford University Press, 2010).

${ }^{23}$ See, e.g., Broome, Weighing Goods; Louis Kaplow and Steven Shavell, Fairness versus Welfare (Cambridge: Harvard University Press, 2002); Bertil Tungodden, "The Value of Equality," Economics and Philosophy 19 (2003): $1-44$.
} 
Although the Pareto principles in some currency may also flow from non-justice components of morality, I am claiming here that the principles have a firm, separate, grounding in justice. If by "justice" we mean that part of morality supervenient on the totality of comparisons from each person's standpoint, then this claim is hard to deny. Again, if $x$ is ranked equal to $y$ by each person-centered ranking, or if $z$ is ranked higher than $w$ by at least one such ranking and at least as high by all, then only an impersonal factor-some factor outside the collection of personal-centered comparisons-would warrant the conclusion that $x$ and $y$ are not equally morally good, or that $z$ is not morally better than $y$. But this factor, if there is one, would not be relevant to justice - and so we should endorse that $x$ and $y$ are equally just, and that $z$ is more just than $w$.

Finally (as the last few sentences already suggest) my position here is not that the generic Pareto principles govern the moral ranking of alternatives. Morality may well have impersonal components; the all-factors-considered moral ranking of a set of alternatives will, then, depend both on these impersonal factors and justice. I don't see any reason to insist that this grand ranking conform to the generic Pareto principles. What I do find compelling is that the justice ranking should.

\section{The Claims Framework: Undifferentiated Desert}

The concept of claims, as presented here, is meant to sharpen the idea of justice as grounded in a collection of person-centered comparisons. ${ }^{24}$ Using this concept, we can make progress in nailing down the content of the justice ranking. In particular, we can see why that ranking should conform not only to the generic Pareto principles, but also to the Pigou-Dalton principle.

For the next three Parts, I adopt the well-being currency: alternative $x$ at least as highly ranked as alternative $y$ from the standpoint of $i$ for purposes of justice iff $i$ is at least as well off with $x$ as $y$. We return to the possibility of a different currency in Part VI.

It is assumed that well-being levels are intra- and interpersonally comparable, perhaps with some incompleteness. The combination of a person and an alternative yields some level of well-being for that person; and the well-being level associated with each person-alternative pair is greater than, less than, equal to, or perhaps incomparable with the well-being level of every other person-alternative pair. Well-being differences are also intra- and interpersonally comparable, again perhaps with some incompleteness.

\footnotetext{
${ }^{24}$ Various conceptions of claims or "complaints" have been advanced in the literature as the basis for understanding justice or equality. See, e.g., Larry Temkin, Inequality (New York: Oxford University Press, 1996); Alex Voorhoeve, "How Should We Aggregate Competing Claims?" Ethics 125 (2014): 64-87. A key feature of the conception of claims presented in what follows is that it meshes snugly with the generalized Pareto principles and, thereby, the separateness of persons. Space constraints preclude a comparison of this view to alternative approaches. See Adler, Well-Being and Fair Distribution, 321-37 (comparing claims-across-outcomes to "complaints" as proposed by Temkin).
} 
A claim is a relation between an individual and two alternatives: an individual $i$ has a claim in favor of $x$ over $y$, or in favor of $y$ over $x$, or a null claim between the two, or an incomparable claim. Since well-being is for now our currency, it is posited that claims are valenced by well-being (Valence): individual $i$ has a claim in favor of $x$ over $y$ iff $i$ is better off with $x$ than with $y$; $i$ has a null claim between $x$ and $y$ iff she is equally well off with the two alternatives; $i$ has an incomparable claim between the two iff she is neither better off with $x$, nor better off with $y$, nor equally well off with the two.

When individual claims conflict—when some have claims for $x$ over $y$, while others have claims for $y$ over $x$-we need a rule for determining the claims' comparative strength. This Part considers the simpler case of undifferentiated desert. It is allowed that there may be desert factors that bear upon the strength of individual claims, independent of well-being; but it is assumed that individuals are identically situated with respect to all such factors. Parts IV and V, below, address the possibility that claim strength is modulated by desert on top of well-being.

\section{A. $\quad$ Fundamental Principles: Well-Being Pareto, Pigou-Dalton, Anonymity}

With a well-being currency and undifferentiated desert, a very strong case can be made for each of the following three clusters of principles. I list the principles, and then summarize the case for each.

The Well-Being Pareto Principles. (a) Well-Being Pareto Indifference. If each person is equally well off with alternative $x$ as she is with alternative $y$, then $x$ and $y$ are equally just. (b) Well-Being Strong Pareto. If each person is at least as well off with $y$ as with $x$, and at least one person is strictly better off with $y$, then $y$ is more just than $x$.

Pigou-Dalton. Let alternatives $x$ and $y$ be such that: (1) one individual ("Higher") is better off with $x$ than $y$, while a second ("Lower") is better off with $y$ than $x$; (2) Higher's level of well-being with $x$ is greater than Lower's with $x$, while Higher's level of wellbeing with $y$ is at least as high as Lower's with $y$; (3) the difference between Higher's level of well-being with $x$ and her level of well-being with $y$ is equal to the difference between Lower's level of well-being with $y$ and his level of well-being with $x$; and (4) everyone else is equally well off with the two alternatives. Then $y$ is more just than $x$.

Anonymity. Let the well-being levels of the $N$ individuals with alternative $y$ be a permutation (rearrangement) of their well-being levels with alternative $x$. Then $x$ and $y$ are equally just. ${ }^{25}$

The well-being Pareto principles flow from the generic Pareto principles plus the adoption of a well-being currency. We can equally well support these principles using the

\footnotetext{
${ }^{25}$ More precisely: Let $\pi($.$) be a one-to-one and onto mapping from the set of individuals \{1,2, \ldots, N\}$ onto itself, a so-called permutation mapping. Anonymity then says: if $x$ and $y$ are such that each $i$ with $x$ has the same level of well-being as $\pi(i)$ with $y, x$ and $y$ are equally just.
} 
apparatus of claims. If each person is equally well off with alternative $x$ as he is with alternative $y$, then by Valence each person has a null claim between the two. It follows that $x$ is neither more just than $y$, nor vice versa, and (by a further bit of reasoning) that the two alternatives are equally rather than incomparably just. ${ }^{26}$ If at least one is better off with $y$, and everyone at least as well off, then by Valence there is at least one claim in favor of $y$, and all other claims either also point this way or are null. Surely, then, $y$ is more just than $x$.

The chain of reasoning from the claims framework to Pigou-Dalton is, I believe, equally compelling. Why? By virtue of Valence, Higher has a claim in favor of $x$; Lower has a claim in favor of $y$; and everyone else has null claims. In this case of two conflicting claims, the alternative favored by the stronger claim will be, on balance, more just. But who does have the stronger claim? Surely it is Lower. Consider the plausible factors that, in general, might affect the strength of an affirmative claim: (a) The claimant's well-being difference between the two alternatives; (b) the claimant's well-being level with the two alternatives; (c) her desert. We are assuming undifferentiated desert, and so factor (c) drops away. Crucially, by virtue of the antecedent conditions for the Pigou-Dalton principle, factor (a) drops away too. What Lower stands to gain in welfare, were alternative $y$ to obtain rather than $x$, is exactly what Higher stands to lose. Higher cannot argue (as she might in a different case) that the magnitude of the change in her well-being, between the two alternatives, is larger than the magnitude of the change in Lower's - and thus that her claim is stronger. By the antecedent conditions, these magnitudes are the same.

And so we are left with factor (b). But, surely, this factor, cuts for Lower. Lower can say to Higher: "The well-being level to which you assert a claim (your level with $x$ ) is higher than the well-being level to which I assert a claim (my level with $y$ ). Indeed, if my claim rather than yours is honored, your level (with y) would be no lower than mine. Surely these facts about our well-being levels have some relevance to the comparative strength of our claims." And Lower can continue: "What can you say, in response, to show that $x$ is on balance more just? Nothingnot that I am less deserving, nor (as you might in another case) that the difference the $x / y$ choice makes to your life is larger than the difference it makes to mine."

The Anonymity axiom is defended as follows. Let's say that two alternatives, $x$ and $x^{*}$, are related by a "two-person permutation" if there are two individuals who switch well-being levels (the level of one with $x$ is the same as the level of the other with $x^{*}$, and vice versa), and everyone else's well-being is the same with $x$ as with $x^{*}$. If $x$ and $x^{*}$ are related by a two-person permutation, then only the two "switched" individuals have claims, one for $x$ over $x^{*}$, the other for $x^{*}$ over $x$. By symmetry the two claims are equally strong, and so $x$ and $x^{*}$ are equally just.

\footnotetext{
${ }^{26}$ Any given alternative $x$ is equally just as itself. But the pattern of claims between $x$ and itself is such that each individual has a null claim. Since the pattern of claims between $x$ and $y$ is exactly the same (each with a null claim), there's no warrant for $x$ to be noncomparable with $y$ rather than equally just.
} 
Further, it can be shown that whenever the well-being levels in $y$ are a permutation of the well-being levels in $x, y$ can be reached from $x$ by a series of two-person permutations. ${ }^{27}$ Denote this series as $x, x^{*}, x^{* *}, x^{* * *}, \ldots, y$. By transitivity, $x$ is equally just as $x^{*}$ is equally just as $x^{* *}$ $\ldots$ is equally just as $y$.

\section{B. From the Fundamental Principles to Continuous Prioritarianism}

What characterizes a prioritarian justice ranking? Scholarship on prioritarianism often does not proceed axiomatically. But I believe it is reasonably consistent with the literature to define "prioritarianism" as the class of rankings of alternatives that satisfy the well-being Pareto principles, the Pigou-Dalton principle, and Anonymity - the three clusters of principles set out above - plus an axiom of separability. Separability says that if some individuals in the population of concern are "unaffected" by whether alternative $x$ or $y$ obtains - each such individual has the same well-being level with $x$ as with $y$-then the justice ranking of $x$ versus $y$ is independent of the specific well-being level of each such individual. ${ }^{28}$

But what justifies the Separability axiom? This axiom can be defended by direct appeal to the concept of claims ${ }^{29}$ — although that defense is, admittedly, less compelling than the argument from the claims framework to the well-being Pareto principles, Pigou-Dalton, and Anonymity. A second defense of Separability is pragmatic. Dropping Separability would mean that in assessing the comparative justice of alternatives with a local impact (alternatives that affect only those within some region, or jurisdiction, or those with a certain social role, or living at a particular time), we would need to determine the well-being levels of the local group, the effects of the alternatives on them, and the well-being levels of unaffected individuals in other regions, jurisdictions, generations, etc.

Let's now add some additional axioms to the mix - the four technical axioms of Measurability, Consistency, Completeness, and Continuity.

Measurability. There is a well-being measure $w($.$) , which translates a given alternative$ into a list ("vector") of well-being numbers, one for each individual in the population of

\footnotetext{
${ }^{27}$ See Marshall Hall, Jr., The Theory of Groups (New York: Macmillan, 1959), 60.

${ }^{28}$ Space constraints preclude a detailed defense here of this interpretive claim (concerning what is meant by "prioritarianism"). Nils Holtug, in a recent review chapter, describes prioritarianism as taking the continuous prioritarian form $\sum g\left(w_{i}\right)$ discussed below, which implies that it satisfies the Pareto principles, the Pigou-Dalton principle, Separability, and Anonymity; and Holtug explicitly invokes the first three principles. "Theories of Value Aggregation: Utilitarianism, Egalitarianism, Prioritarianism," in The Oxford Handbook of Value Theory, ed. Iwao Hirose and Jonas Olson (New York: Oxford University Press, 2015), 267-84. In his original presentation of the view, Derek Parfit stresses that prioritarianism "contains the idea that benefits are good" and avoids the Levelling Down objection (strong Pareto); that it gives greater weight to benefits to the worse off (Pigou-Dalton); and that it is unconcerned with how individuals fare relative to others (Separability). Derek Parfit, "Equality or Priority, in The Ideal of Equality, 81-125. As for Anonymity: this axiom formalizes the ideal of impartiality, that no person's wellbeing has greater moral weight simply by virtue of who she is; and there is no hint that Parfit takes prioritarianism to reject that ideal.

${ }^{29}$ Adler, Well-Being and Fair Distribution, ch. 5.
} 
concern. Alternative $x$ becomes the vector $\left(w_{1}^{x}, w_{2}^{x}, \ldots, w_{N}{ }^{x}\right)$, with $w_{i}^{x}$ the well-being number assigned by $w($.$) to individual i$ given alternative $x .^{30}$

These $w$ numbers track individual well-being. Individual $i$ with alternative $x$ is at least as well off as individual $j$ with alternative $y$ iff $w_{i}{ }^{x}$ is at least as large as $w_{j}{ }^{y}$-and similarly for well-being differences.

Consistency. If $x$ and $y$ are in some set $\mathbf{S}$ of alternatives, and the justice ranking of $\mathbf{S}$ is such as to rank $x$ at least as just as $y$, then the justice ranking of every other set to which $x$ and $y$ both belong must also be such as to rank $x$ at least as just as $y$.

Completeness. For every two alternatives, either the first is more just than the second, or less just, or equally just. In other words, it is never the case that alternatives are incomparably just.

Continuity. If one well-being vector is ranked more just than a second, then there will always be some zone around the first vector such that every vector in this zone is also more just than the second.

These four technical axioms can be given a pragmatic justification, ${ }^{31}$ and Consistency can also be defended on substantive grounds. ${ }^{32}$

The following can now be demonstrated. (See Appendix for the details.) The fundamental axioms (the well-being Pareto principles, Pigou-Dalton, and Anonymity), plus Separability, plus the four technical axioms, imply the following: The justice ranking of alternatives is mirrored by the sum of concavely transformed individual well-being. We start with each individual well-being number in the vector corresponding to a given alternative, and "transform" that well-being number using a strictly increasing and concave function $g($.) —as in Figure 1 below. Alternative $x$ is at least as just as alternative $y$ iff the sum of the concavely transformed well-being numbers corresponding to $x$ is at least as large as the sum of the concavely transformed well-being numbers corresponding to $y$.

\footnotetext{
${ }^{30}$ Note that Measurability precludes incompleteness in the well-being ranking for a given person.

${ }^{31}$ Measurability means that each individual's welfare-relevant attributes can be summarized as a single well-being number. A decisionmaker can then think about the justice ranking of alternatives as a ranking of well-being vectors, rather than - in a much more complex way - as a comparison of allocations of attribute bundles to all the individuals in the population of concern. Consistency allows the decisionmaker to develop a single ranking of well-being vectors that will guide her ranking of each set of alternatives, independent of the specific membership of that setrather than needing to have a plurality of rankings of vectors. Completeness and Continuity, together, imply that the justice ranking of vectors can be represented via a continuous real-valued function $J($.). Vector $\mathbf{v}$ at least as just as vector $\mathbf{v}^{*}$ iff $J(\mathbf{v}) \geq J\left(\mathbf{v}^{*}\right)$. A wide range of mathematical tools become available for determining what justice recommends. For example, identifying the most just alternative in some set reduces to the problem of maximizing the value of $J($.$) .$

${ }^{32}$ See below, Part VI.
} 


\section{Figure 1}

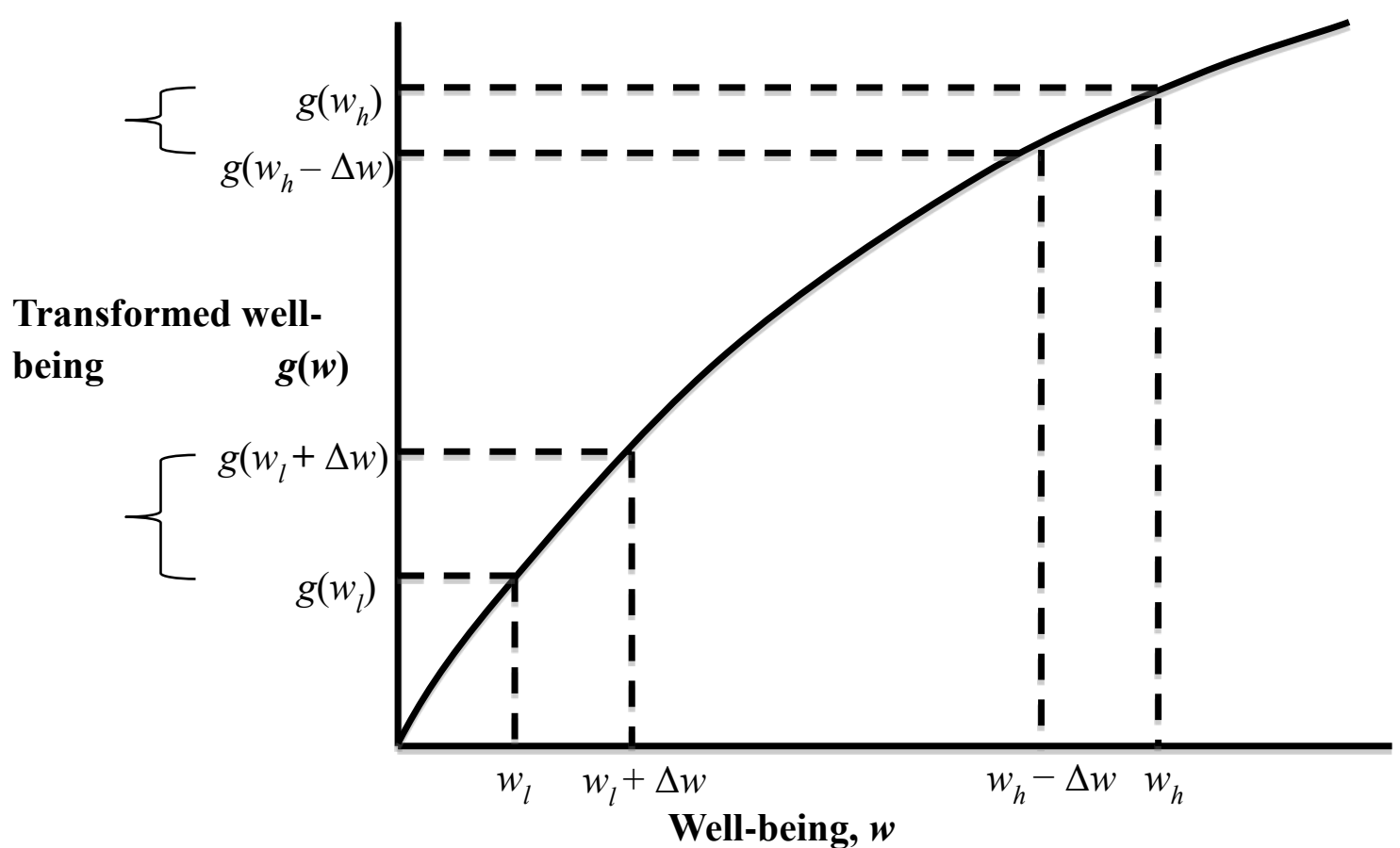

Explanation: The figure displays a strictly increasing and concave $g($.$) and specifically illustrates why the$ $\sum g\left(w_{i}\right)$ formula satisfies the Pigou-Dalton principle. A change in well-being by amount $\Delta w$ that occurs at a higher well-being level ( $w_{h}$ as opposed to $w_{l}$ ) produces a smaller change in transformed well-being.

For short, let's refer to a justice ranking of this sort as "continuous prioritarianism," and let's abbreviate the formula for the sum of concavely transformed well-being as $\sum g\left(w_{i}\right)$. Insofar as the extant literature on prioritarianism employs a mathematical representation, it often does use the formula $\sum g\left(w_{i}\right) .{ }^{33}$ To repeat: this formula is a tractable specification of prioritarianism that emerges by combining the principles that capture the core of prioritarianism (the well-being Pareto principles, Pigou-Dalton, Anonymity and Separability) with four further, technical axioms. $^{34}$

\footnotetext{
${ }^{33}$ See, e.g., Holtug, "Theories of Value Aggregation"; John Broome, "Equality versus Priority: A Useful Distinction," Economics and Philosophy 31 (2015): 219-28; Campbell Brown, "Priority or Sufficiency ... or Both?" Economics and Philosophy 21 (2005): 199-220; Wlodek Rabinowicz, "Prioritarianism for Prospects," Utilitas 14 (2002): 2-21.

${ }^{34}$ In an important article, Alex Voorhoeve and Michael Otsuka have argued that prioritarianism does not respect the separateness of persons. "Why it Matters that Some are Worse Off than Others: An Argument against the Priority View," Philosophy and Public Affairs 37 (2009): 171-99. I cannot address their arguments here, which implicate
} 


\section{Desert-Modulated Claims}

\section{A. Four Fundamental Principles}

Let's now posit that individuals have an attribute, "desert," which works as follows. First, for any person and any alternative, that person has some level of desert with that alternative. Second, these desert levels are intra- and interpersonally comparable, perhaps with some incompleteness. Finally, desert levels figure into the strength of claims, independent of well-being. A higher desert level tends to strengthen an individual's claim.

In reading through the analysis, the reader might be helped by having in mind a specific conception of desert. In particular, she might think of desert as degree of prudence. ${ }^{35}$ The more carefully and conscientiously I have attended to my own interests, the more powerful my claim, ceteris paribus. This conception resonates with the literature on luck egalitarianism. Imagine that John and Sue are both badly off, and equally so. John is badly off because of imprudent choices, while Sue has chosen well but is badly off because of unfortunate events that she could not control or foresee. Then, intuitively, John's claim to be made better off is weaker than Sue's. ${ }^{36}$

While thinking of desert as prudence is useful in concretizing what follows, the analysis in no way rests upon this conception of desert. Rather, desert is anything about an individual, other than her well-being, that modulates the strength of her claims. ${ }^{37}$

With desert in play, we can use the claims framework to argue for four fundamental clusters of axioms, not three: the well-being Pareto principles, a desert-modulated (DM) PigouDalton Principle, desert-modulated (DM) Anonymity, and Priority for the More Deserving. (The well-being Pareto principles are the same as above, but are repeated for convenience.)

The Well-Being Pareto Principles. (a) Well-Being Pareto Indifference: If each person is equally well off with alternative $x$ as she is with alternative $y$, then $x$ and $y$ are equally just. (b) Well-Being Strong Pareto: If each person is at least as well off with $y$ as with $x$, and at least one person is strictly better off with $y$, then $y$ is more just than $x$.

\footnotetext{
the complex problem of prioritarianism under uncertainty. Suffice it to say that (as I see it) nothing in their arguments calls into question the fundamental axioms that I have claimed to flow directly from the separateness of persons, namely Pareto, Pigou-Dalton, and Anonymity.

${ }^{35}$ See Peter Vallentyne, "Brute Luck Equality and Desert," in Desert and Justice, 169-85.

${ }^{36}$ On the relevance of individual prudence for purposes of a luck-egalitarian view of distributive justice, see, e.g., Arneson, "Welfare Should be the Currency of Justice"; Peter Vallentyne, "Brute Luck, Option Luck, and Equality of Initial Opportunities," Ethics 112 (2002): 529-57.

${ }^{37}$ See Arneson, "Desert and Equality," arguing that desert for purposes of justice and desert prioritarianism is moral conscientiousness; Kasper Lippert-Rasmussen, "Luck-Egalitarianism: Faults and Collective Choice," Economics and Philosophy 27 (2011): 151-73, arguing that an individual is at fault for purposes of distributive justice if she is prudentially faulty, except if a prudentially fault choice is morally motivated.
} 
DM Pigou-Dalton. Let alternatives $x$ and $y$ be such that: (1) one individual ("Higher") is better off with $x$ than $y$, while a second ("Lower") is better off with $y$ than $x$; (2) Higher's level of well-being with $x$ is greater than Lower's with $x$, while Higher's level of wellbeing with $y$ is at least as high as Lower's with $y$; (3) the difference between Higher's level of well-being with $x$ and her level of well-being with $y$ is equal to the difference between Lower's level of well-being with $y$ and his level of well-being with $x$; (4) Lower (with either alternative) is at least as deserving as Higher (with either alternative); (5) everyone else is equally well off with the two alternatives. Then $y$ is more just than $x$.

DM Anonymity. Let the desert and well-being levels of the $N$ individuals with alternative $y$ be a permutation (rearrangement) of their desert and well-being levels with alternative $x$. Then $x$ and $y$ are equally just. ${ }^{38}$

Priority for the More Deserving: Let alternatives $x$ and $y$ be such that: (1) the desert level of one individual ("Desi") with either alternative is greater than the desert level of a second individual ("Lesi") with either alternative; (2) Desi's level of well-being with $y$ is equal to Lesi's level of well-being with $x$, and vice versa; (3) Desi is better off with $y$ than $x$ (and thus Lesi is better off with $x$ than $y$ ); (4) everyone else has the same well-being level with $x$ as with $y$; (5) everyone has the same desert level with $x$ as with $y$. Then $y$ is more just than $x .{ }^{39}$

Now let's hear the arguments for the principles. That for the well-being Pareto principles is the same as above.

Above, in arguing for the ordinary Pigou Dalton principle (for the case of undifferentiated desert), we observed that three factors might affect the strength of someone's claim between two alternatives: her well-being levels with the two alternatives, her difference in well-being between the two, and her desert levels with the two. We can use this observation to defend both DM Pigou-Dalton and Priority for the More Deserving. Consider, first, DM PigouDalton. We need to show that Lower's claim to $y$ over $x$ is stronger than Higher's claim to $x$ over $y$; if so, $y$ will be more just, since everyone else has null claims. The well-being-level factor tends to give Lower the stronger claim: he is worse off than Higher with at least one of the alternatives, and no better off with either. The well-being-difference factor drops away, since the

\footnotetext{
${ }^{38}$ More precisely: Let $\pi($.$) be a permutation mapping on the set of individuals (see above, note 25). If x$ and $y$ are such that, for each $i$, the well-being level of $i$ with $x$ is equal to the well-being level of $\pi(i)$ with $y$ and the desert level of $i$ with $x$ is equal to the desert level of $\pi(i)$ with $y$, then: $x$ and $y$ are equally just.

${ }^{39}$ Why has proviso (5) been added to this axiom? After all, proviso (4) suffices to establish that everyone other than Desi and Lesi has null claims between $x$ and $y$. Why is it also required that everyone's desert levels be unaffected? The answer is that Priority for the More Deserving without proviso (5) may be internally inconsistent; there may be no transitive ranking of the set $\mathbf{S}$ that satisfies this principle. See Appendix. By contrast, it is not hard to see that the ranking of any $\mathbf{S}$ using the desert-modulated continuous formula described below in Part IV.B. will always satisfy Priority for the More Deserving with proviso (5). To be sure, even with that proviso the principle can come into conflict with the Pareto principles. See Parts V, VI.
} 
differences are equal. Finally, the desert factor does not cut in favor of Higher (since Lower's desert level with either alternative is at least as great as Higher's with either), and may affirmatively weigh in favor of Lower (if Lower's desert level is strictly greater). On balance, then, Lower's claim to $y$ over $x$ is stronger than Higher's claim to $x$ over $y$.

Consider, next, Priority for the More Deserving. We need here to show that Desi's claim to $y$ over $x$ is stronger than Lesi's to $x$ over $y$. The well-being-level factor, now, does not weigh in favor of either individual with respect to claim strength. (Desi is better off than Lesi with $y$, but Lesi is better off than Desi with $x$, and indeed the two just swap well-being levels.) The well-being-difference factor, too, does not favor either individual, since the differences are equal. Finally, since Desi is unambiguously more deserving than Lesi (Desi's desert level with each of the alternatives is higher than Lesi's with each), the desert factor tends to give Desi the stronger claim. On balance, then, Desi's claim to $y$ over $x$ is stronger than Lesi's claim to $x$ over $y$.

A powerful passage from Arneson makes the case for Priority for the More Deserving, using the specific conception of desert as prudence.

\begin{abstract}
Suppose that two individuals have identical welfare at present and that the social planner can choose between two policies, policy A, which confers a one unit welfare gain on the first individual, Smith, and policy B, which confers a one unit welfare gain on the second individual, Jones. On a welfarist view, it seems there is nothing to choose between Smith and Jones .... But suppose we add to the story the detail that whereas both Smith and Jones have low welfare at present, Smith has been prudent and responsible in the conduct of his life but suffered an accident through no fault of his own, whereas Jones, born to every advantage, has behaved in a thoroughly irresponsible fashion and culpably mismanaged his life in all respects. We may then feel that justice should favor aid to Smith over aid to Jones .... ${ }^{40}$
\end{abstract}

Finally, the argument for DM Anonymity just generalizes the argument above for Anonymity (in the case of undifferentiated desert). Assume that $x^{*}$ is related to $x$ by a twoperson permutation of combinations of well-being and desert levels. Call the two individuals Able and Bob. Able's well-being level in $x^{*}$ is the same as Bob's in $x$, and Able's desert level in $x^{*}$ is the same as Bob's in $x$. Conversely, Bob's well-being level in $x^{*}$ is the same as Able's in $x$, and Bob's desert level in $x^{*}$ is the same as Able's in $x$. Everyone else's well-being level and desert level does not vary between the two alternatives. Then, by symmetry, Able and Bob have equally strong claims between $x$ and $x^{*}$, and since everyone else has null claims, the two alternatives are equally just. Since every permutation of combinations of desert and well-being levels is a series of two-person permutations, DM Anonymity follows by transitivity.

To be sure, the fact that persuasive arguments can be separately mounted for each of the four clusters of principles does not mean that we should, on balance, endorse all of them. In particular, if the principles turn out to be logically inconsistent with respect to some set of alternatives $\mathbf{S}$ - that is, no justice ranking of $\mathbf{S}$ satisfies all of them-then we will be forced to abandon the combination of the principles, at least with respect to $\mathbf{S}$.

40 "Welfare Should be the Currency of Justice," 504. 
However, in the case of intrapersonally fixed desert, the principles are logically consistent. Let's say that a set of alternatives is characterized by "intrapersonally fixed desert" if each individual's desert level with any alternative in the set is the same as her desert level with any other alternative. In any such set (at least if we add a technical axiom regarding measurability), there is a ranking that satisfies the Well-Being Pareto Principles, DM PigouDalton, DM Anonymity, and Priority for the More Deserving. ${ }^{41}$

\section{B. From the Fundamental Principles to Desert-Modulated (DM) Continuous}

\section{Prioritarianism}

Recall that, in the discussion of undifferentiated desert, we defined "continuous prioritarianism" as the ranking of alternatives using the formula $\sum g\left(w_{i}\right)$. And we observed that this formula follows from the combination of the well-being Pareto principles, the Pigou-Dalton principle and Anonymity together with Separability and four technical axioms.

This discussion generalizes to the case of differentiated desert. Separability and the technical axioms are reworked for that case, as follows:

DM Separability. Assume that some individuals are unaffected, in terms of both wellbeing and desert, by whether alternative $x$ or $y$ obtains. Then the ranking of $x$ versus $y$ is independent of the well-being and desert levels of these individuals.

DM Measurability. There is a measure $w($.$) and a measure d($.$) that track, respectively,$ individual well-being and individual desert, and that translate each alternative into a vector of pairs of well-being and desert numbers - one pair for each individual in the population of concern. Alternative $x$ becomes the vector $\left(\left(w_{1}^{x}, d_{1}^{x}\right),\left(w_{2}^{x}, d_{2}^{x}\right), \ldots,\left(w_{N}{ }^{x}\right.\right.$, $\left.d_{N}{ }^{x}\right)$.

Consistency. If $x$ and $y$ are in some set $\mathbf{S}$ of alternatives, and the justice ranking of $\mathbf{S}$ is such as to rank $x$ at least as just as $y$, then the justice ranking of every other set to which $x$ and $y$ both belong must also be such as to rank $x$ at least as just as $y$.

Completeness. For every two alternatives, either the first is more just than the second, or less just, or equally just. In other words, it is never the case that alternatives are incomparably just.

DM Continuity. If one well-being/desert vector is ranked more just than a second, then there will always be some zone around the first vector such that every vector in this zone is also more just than the second.

\footnotetext{
${ }^{41}$ See immediately below Part IV.B. If DM Measurability holds true, then clearly the ranking of any set with intrapersonally fixed desert using the formula $\Sigma f\left(w_{i}, d_{i}\right)$ satisfies the Well-Being Pareto principles, DM PigouDalton, DM Anonymity, and Priority for the More Deserving. I have not established that there is always such a ranking absent DM Measurability.
} 
The upshot of the new, expanded group of fundamental axioms (Pareto, DM PigouDalton, DM Anonymity, Priority for the More Deserving), plus DM Separability, plus the reworked technical axioms (DM Measurability, Consistency, Completeness, DM Continuity) is an approach that I'll term "desert-modulated continuous prioritarianism." (See Appendix for a proof sketch.) There is a two-place function $f($.), which takes as its inputs both an individual well-being number and an individual desert number. This function has the shape displayed in Figure 2. First, holding constant desert, $f($.) increases as well-being does, with a concave arc. Second, at a given level of well-being, the rate of increase of $f($.) with respect to well-being, i.e., its slope with respect to well-being, increases as the level of desert increases ("the slope condition").

\section{Figure 2}

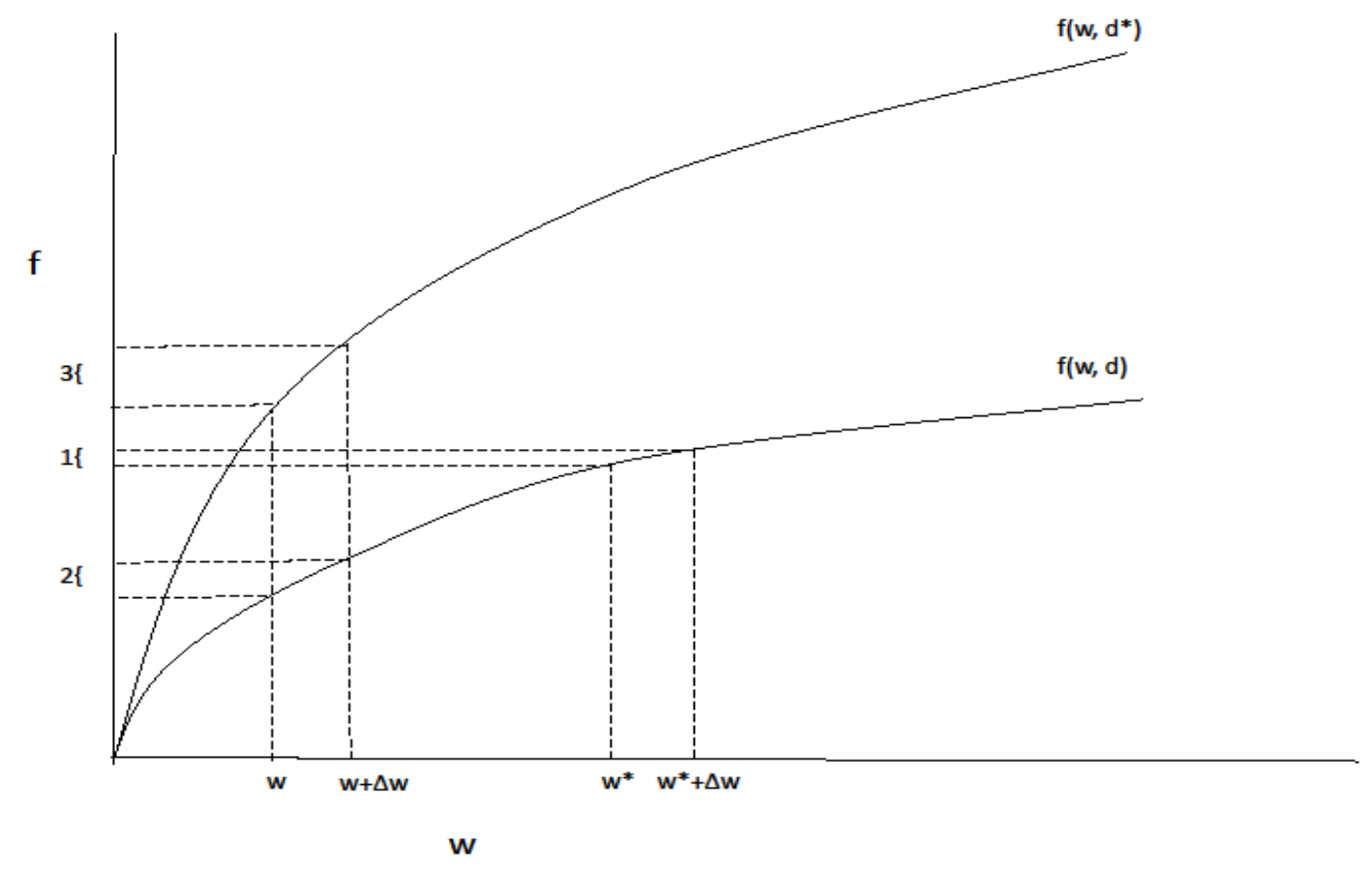

Explanation: The figure illustrates $f($.$) as a function of well-being w$ for two different levels of desert, with $d^{*}>d$. Note that $f($.$) is not merely strictly increasing and concave in w$ for each given desert level, but satisfies the slope condition; at each level of $w, f\left(w, d^{*}\right)$ has a greater slope than $f(w, d)$. The dashed lines illustrate how the $\sum f\left(w_{i}, d_{i}\right)$ formula satisfies DM Pigou Dalton and Priority for the More Deserving.

The justice ranking of alternatives corresponds to the sum of these $f$ values: alternative $x$ is at least as just as $y$ iff the sum of individual $f$ values for the well-being/desert vector corresponding to $x$ is at least as large as the sum of individual $f$ values for the well-being/desert vector corresponding to $y$. 
Let's use the symbol $\sum f\left(w_{i}, d_{i}\right)$ to denote desert-modulated continuous prioritarianism. This is indeed an intuitive generalization of continuous prioritarianism, $\sum g\left(w_{i}\right)$. If desert is intrapersonally fixed and each person has the same desert level as every other person, the $\sum f\left(w_{\mathrm{i}}\right.$, $\left.d_{i}\right)$ formula reduces to $\sum g\left(w_{i}\right)$ - since $f($.$) is strictly increasing and concave in well-being, just as$ $g($.$) is.$

If desert is intrapersonally fixed but there is interpersonal variation in individual desert levels, the axiom Priority for the More Deserving comes into play and $\Sigma f\left(w_{i}, d_{i}\right)$ satisfies this axiom by virtue of the slope condition. Further, as long desert is intrapersonally fixed, $\Sigma f\left(w_{i}, d_{i}\right)$ satisfies DM Pigou Dalton (by virtue of the slope condition plus the fact that $f($.) is concave in well-being) and the well-being Pareto principles. ${ }^{42}$ It is also straightforward to see that $\Sigma f\left(w_{i}, d_{i}\right)$ satisfies DM Anonymity and DM Separability.

\section{Desert-Modulated Claims and Intrapersonally Variable Desert: The Conflict between the Pareto Principle and Priority for the More Deserving}

While desert-modulated continuous prioritarianism, $\Sigma f\left(w_{i}, d_{i}\right)$, satisfies the well-being Pareto principles in ranking a set of alternatives $\mathbf{S}$ if desert is intrapersonally fixed in $\mathbf{S}$, it does not necessarily do so if desert is intrapersonally variable in $\mathbf{S} .^{43}$ If we hold constant an individual's well-being but change her desert, her $f$ value can change. Thus, with intrapersonally variable desert, the sum of $f$ values can change even if everyone's well-being does not changein violation of well-being Pareto indifference. Similarly, if we reduce an individual's well-being, but change her desert, her $f$ value can increase. Thus, with intrapersonally variable desert, the sum of $f$ values can increase even if some individuals' well-being is reduced and no one's is increased —in violation of well-being strong Pareto.

These effects can be visualized in Figure 2 above, and are illustrated with a specific example in Table 1 immediately below.

\footnotetext{
${ }^{42}$ If each person is equally well off with $x$ and $y$, then—with intrapersonally fixed desert—each person's $f$ value does not change. And if some person is better off with $y$ than $x$, and her desert does not change, her $f$ value goes up, since $f($.) is increasing in well-being.

${ }^{43}$ Desert is "intrapersonally variable" in some set of alternatives if it is not intrapersonally fixed. That is: there is at least one person, and at least one pair of alternatives, such that the person's desert level with the first is not the same as her desert level with the second.
} 


\section{Table 1}

\begin{tabular}{|c|c|c|c|}
\hline & Alternative $x$ & $\underline{\text { Alternative } y}$ & Alternative $z$ \\
\hline Sofia & $100,2(20)$ & $100,3(30)$ & $98,3(29.7)$ \\
\hline Gabriel & $25,3 \quad(15)$ & $25,2 \quad(10)$ & $24,2(9.8)$ \\
\hline Sum of $f($.$) values$ & 35 & 40 & 39.5 \\
\hline
\end{tabular}

Explanation: In this example, $f\left(w_{i}, d_{i}\right)$ is the desert level $d_{i}$ multiplied by the square root of the well-being level $w_{i}$. The first two numbers in each cell show each individual's well-being and desert level; her $f$ value is in parentheses.

Because Sofia and Gabriel are, each, equally well off with $y$ as $x$, well-being Pareto indifference requires that the two alternatives be ranked equally just. But the sum of $f$ values is greater for $y$ than for $x$.

Because Sofia and Gabriel are, each, worse off with $z$ than with $x$, well-being strong Pareto requires that $z$ be ranked as less just than $x$. But the sum of $f$ values is greater for $z$ than for $x$.

Why, more abstractly, can desert-modulated continuous prioritarianism conflict with the well-being Pareto principles in the case of intrapersonally variable desert? The culprit is Priority for the More Deserving. There are two incompatibilities, here, concerning Priority for the More Deserving and, respectively, Well-being Pareto Indifference and Well-being Strong Pareto.

Incompatibilities between Priority for the More Deserving and the Well-Being Pareto Principles

Assume that the set of alternatives $\mathbf{S}$ is characterized by intrapersonally variable desert.

(1) It is possible that Priority for the More Deserving and Well-Being Pareto Indifference are inconsistent with respect to $\mathbf{S}$. That is, there may be no justice ranking of $\mathbf{S}$ which satisfies both of these axioms.

(2) If we assume, further, that the justice ranking of S satisfies DM Measurability, DM Anonymity, and DM Continuity, it is possible that Priority for the More Deserving and Well-Being Strong Pareto are inconsistent with respect to $\mathbf{S}$.

The first incompatibility (between Priority for the More Deserving and Well-Being Pareto Indifference) is illustrated by Table 2 below. The second is illustrated by Table 3 . 


\section{Table 2}

\begin{tabular}{|c|c|c|}
\hline & Alternative $x$ & Alternative $y$ \\
\hline Jim & $\mathrm{W}_{\mathrm{Jim}}{ }^{*}, \mathrm{D}_{\mathrm{Jim}}$ & $\mathrm{W}_{\text {Jim }}, \mathrm{D}_{\mathrm{Jim}}$ \\
\hline \multirow[t]{2}{*}{ Sally } & $\mathrm{W}_{\text {Sally }}, \mathrm{D}_{\text {Sally }}{ }^{*}$ & $\mathrm{~W}_{\text {Sally }}{ }^{*}, \mathrm{D}_{\text {Sally }}{ }^{*}$ \\
\hline & Alternative $z$ & Alternative $z z$ \\
\hline Jim & $\mathrm{W}_{\mathrm{Jim}} *, \mathrm{D}_{\mathrm{Jim}} *$ & $\mathrm{~W}_{\mathrm{Jim}}, \mathrm{D}_{\mathrm{Jim}}{ }^{*}$ \\
\hline Sally & $\mathrm{W}_{\text {Sally }}, \mathrm{D}_{\text {Sally }}$ & $\mathrm{W}_{\text {Sally }}{ }^{*}, \mathrm{D}_{\text {Sally }}$ \\
\hline
\end{tabular}

Explanation: The symbols $\mathrm{W}_{\mathrm{Jim}}$ and $\mathrm{W}_{\mathrm{Jim}}{ }^{*}$ are not numbers. Rather, each denotes a possible well-being basis for Jim: some possible combination of facts that, if it obtains, suffices to determine how well off Jim is. Similarly, $\mathrm{W}_{\text {Sally }}$ and $\mathrm{W}_{\text {Sally }}{ }^{*}$ are possible well-being bases for Sally. Further, the intra and interpersonal comparisons to which these well-being bases give rise are as follows. "W" denotes one and the same level of well-being, whether subscripted to Jim or Sally. (For example, in the above table, Jim with alternative $y$ is equally well off as Jim with alternative $z z$, and equally well off as Sally with alternatives $x$ and $z$.) Similarly, $\mathrm{W}^{*}$ denotes one and the same level of well-being. Finally, $\mathrm{W}^{*}$ denotes a higher level of wellbeing than $\mathrm{W}$.

Similarly, the symbols $\mathrm{D}_{\mathrm{Jim}}, \mathrm{D}_{\mathrm{Jim}} *$, $\mathrm{D}_{\text {Sally }}, \mathrm{D}_{\text {Sally }} *$ are not numbers, but denote a possible desert basis for Jim and Sally, respectively. Further, D denotes one and the same level of desert, whether subscripted to Jim or Sally; and D* denotes a higher level of desert, whether subscripted to Jim or Sally.

Well-being Pareto Indifference requires that (1) $y$ be ranked equally just as $z z$ and that $x$ be ranked equally just as $z$. Priority for the More Deserving requires that (2) $y$ be ranked more just than $x$ and that $z$ be ranked more just than $z z$. However, given transitivity of the justice ranking, (1) and (2) can't both be true.

\section{Table 3}

$\begin{array}{lllll} & \underline{\text { Alt. } x} & \underline{\text { Alt. } y} & \underline{\text { Alt. } y+} & \underline{\text { Alt. } z+} \\ \operatorname{Jim} & w^{*}, d & w, d & w-\varepsilon, d & w^{*}-\varepsilon, d^{*} \\ \text { Sally } & w, d^{*} & w^{*}, d^{*} & w^{*}-\varepsilon, d^{*} & w-\varepsilon, d\end{array}$

Explanation: $w^{*}$ and $w$ are well-being numbers, with $w^{*}>w . d^{*}$ and $d$ are desert numbers, with $d^{*}>d$. These numbers can be used in the table because we are now assuming DM Measurability.

Priority for the More Deserving requires that $y$ be ranked more just than $x$. By DM Continuity, $y+$ is also more just than $x$ for $\varepsilon$ sufficiently small. By DM Anonymity, $z+$ is equally just as $y+$. By transitivity, then, $z+$ is more just than $x$. But this contradicts Well-Being Strong Pareto: note that each individual's well-being level with $z+$ is less than his or her well-being level with $x$. 
What happens if we drop DM Continuity? In that case, at least if we assume DM Measurability, Well-Being Strong Pareto and Priority for the More Deserving are logically consistent in all sets of alternatives (even with intrapersonally variable desert). ${ }^{44}$

However, even with DM Continuity dropped, Well-Being Strong Pareto creates tight constraints on the role of desert in modulating claim strength. Let's say that "Minimal Significance for Desert" holds true if desert functions only as a tiebreaker.

Minimal Significance for Desert: Assume that two alternatives $x$ and $y$ are such that: (1) one individual ("Able") is better off with $x$ than $y$, while a second individual ("Baker") is better off with $y$ than $x$; (2) the difference between Able's well-being level with $x$ and $y$ is larger than the difference between Baker's well-being level with $y$ and $x$; (3) Able's wellbeing level with $y$ is equal to Baker's with $x$; (4) everyone else is just as well off with $x$ as with $y$. Then $y$ is not more just than $x$, regardless of the desert levels of Able and Baker.

As between individuals at the same well-being level, Priority for the More Deserving says that justice channels a fixed benefit to the more deserving individual rather than to the less deserving one. Conversely, Minimal Significance for Desert says that justice does not channel a smaller benefit to the more deserving individual in preference to a larger benefit for the less deserving one.

We can now show that (assuming only DM Anonymity), if Minimal Significance for Desert does not hold true, there will be some set of alternatives with intrapersonally variable desert in which Well-Being Strong Pareto is violated. See Table 4.

\footnotetext{
${ }^{44}$ Consider, for example, a two-step approach that is continuous-prioritarian except in using the desert-modulated continuous prioritarian formula as a tiebreaker. This says: (1) Alternative $x$ is more just than $y$ if ranked higher by the $\sum g\left(w_{i}\right)$ formula; (2) if the two alternatives are ranked equal by the $\sum g\left(w_{i}\right)$ formula, then $x$ is more just than $y$ if ranked higher by the $\sum f\left(w_{i}, d_{i}\right)$ formula; (3) otherwise $x$ and $y$ are equally just. This two-step approach (which can violate DM Continuity) always satisfies Priority for the More Deserving and Well-Being Strong Pareto.
} 


\section{Table 4}

$\begin{array}{llll} & \text { Alt. } x & \text { Alt.y } & \underline{\text { Alt. } z} \\ \text { Jim } & \mathrm{W}_{\mathrm{Jim}}{ }^{* *}, \mathrm{D}_{\mathrm{Jim}} & \mathrm{W}_{\mathrm{Jim}}, \mathrm{D}_{\mathrm{Jim}} & \mathrm{W}_{\mathrm{Jim}}{ }^{*}, \mathrm{D}_{\mathrm{Jim}} * \\ \text { Sally } & \mathrm{W}_{\text {Sally }}, \mathrm{D}_{\text {Sally }} * & \mathrm{~W}_{\text {Sally }}{ }^{*}, \mathrm{D}_{\text {Sally }} * & \mathrm{~W}_{\text {Sally, }}, \mathrm{D}_{\text {Sally }}\end{array}$

Explanation: $\mathrm{W}$ and D are not numbers, but rather indicate the well-being or desert basis of Sally or Jim, depending on the subscript. Let $\mathrm{W}^{*}$ denote a greater well-being level than $\mathrm{W}$, and $\mathrm{W}^{* *}$ a yet greater wellbeing level. (Thus Jim's well-being difference between alternatives $x$ and $y$ is greater than Sally's wellbeing difference between alternatives $y$ and $x$.) $\mathrm{D}^{*}$ indicates a higher level of desert than $\mathrm{D}$.

If Minimal Significance is dropped, then it is possible for there to be a pair of alternatives $x$ and $y$ as displayed here such that $y$ is more just than $x$. Consider now the alternative set that includes $x, y$, and $z$. By DM Anonymity, $\mathrm{z}$ is equally just as $y$. Because $y$ is more just than $x$, it follows by transitivity that $z$ is more just than $x$. But this violates Well-Being Strong Pareto, since one individual (Jim) is worse off with $z$ than $x$, while the other (Sally) is equally well off.

It is important to be clear about the nature of the conflicts between Priority for the More Deserving and the well-being Pareto principles illustrated by Tables 2 and 3. These tables do not show that Priority for the More Deserving conflicts with the Pareto principles in every set of alternatives that has intrapersonally variable desert. Rather, these tables demonstrate that there are some sets, with intrapersonally variable desert, in which Priority for the More Deserving conflicts with the well-being Pareto principles. Similarly, Table 4 does not show that dropping Minimal Significance yields a conflict with Well-being Strong Pareto in every set of alternatives with intrapersonally variable desert. Rather, it shows that doing so yields a conflict in some such sets.

\section{Conflict-Resolution Strategies}

Part V showed that conflicts between Priority for the More Deserving and the well-being Pareto principles can arise, specifically in the case of intrapersonally variable desert. For short, let's refer to the conflicts there described as "Conflict." Conflict reveals, it seems, an internal contradiction in the project of desert-modulated claims - in the attempt to construct a framework whereby desert functions as one determinant of claim strength. Can the contradiction be resolved? I consider various possible strategies for doing so-first, strategies that maintain wellbeing as the currency for justice; and second, strategies that shift to a different currency.

\section{A. Well-Being as the Currency for Justice}

Under this general heading, I'll consider two groups of approaches for handling Conflict: those that drop the well-being Pareto principles, and those that retain them. Neither avenue is appealing. 


\section{(1) Dropping the Well-Being Pareto Principles}

If we drop the well-being Pareto principles, Priority for the More Deserving can be satisfied in every set of alternatives consistently with the remaining fundamental axioms (DM Pigou-Dalton and DM Anonymity). ${ }^{45}$ But if well-being is the currency of justice-if comparisons of alternatives from the standpoint of each person are just comparisons in light of her well-being - then the valencing of claims in terms of well-being seems the most fundamental part of the claims framework. Surely, in reflective equilibrium, we should preserve this and abandon the initial idea that both desert and well-being might interact to determine claim strength, rather than vice versa.

It is sometimes thought that Well-Being Strong Pareto is even more compelling than Well-Being Pareto Indifference. ${ }^{46}$ This thought seems misconceived. In any event, retaining Well-Being Strong Pareto while dropping Pareto Indifference is hardly an attractive path to handling Conflict. First, we are required to give up the bundle of technical axioms that facilitate real-world choice in light of justice. ${ }^{47}$ Second, as shown above, Well-Being Strong Pareto forces desert to have only Minimal Significance with respect to claim strength.

\section{(2) Retaining the Well-Being Pareto Principles}

Since Conflict occurs only with intrapersonally variable desert, we might insist on intrapersonally fixed desert. Every set of alternatives should be such that no person's desert varies across alternatives. But this is absurd. Desert, whatever exactly it might be, is surely not "built into" a person's identity. Someone can become more or less deserving while remaining the same person. This is true for prudence, moral conscientiousness, and every other plausible conception of desert. If so, it is possible that any given person might find herself at any one of a plurality of desert levels; and thus a decisionmaker should be free to count as possible a set of alternatives in which desert levels vary intrapersonally.

A different thought is that any set of alternatives in which desert varies intrapersonally should be divided into subsets within which desert is intrapersonally fixed; and we should consider alternatives in different such subsets as incomparable with respect to justice, rather than more, less, or equally just. But a moment's thought shows that this proposal conflicts with the well-being Pareto principles. If $x$ and $y$ are such that some are better off with $x$, and everyone is at least as well off, then Well-Being Strong Pareto requires that $x$ be ranked more just than $y-$ not that they be incomparable.

\footnotetext{
45 The two-step rule described above in note 44 does so.

46 This view is implicit in Louis Kaplow and Steven Shavell, "Any Non-welfarist Method of Policy Assessment Violates the Pareto Principle," Journal of Political Economy 109 (2001): 281-86.

${ }^{47}$ Recall that (as illustrated in Table 3), the combination of the technical axioms DM Measurability, DM Anonymity and DM Continuity can produce a conflict between Well-Being Strong Pareto and Priority for the More Deserving.
} 
Another strategy is to limit the applicability of Priority for the More Deserving to certain sets. As already emphasized, Priority for the More Deserving does not conflict with the wellbeing Pareto principles in all sets. Rather, the conflict arises in some (not all) sets of alternatives with intrapersonally variable desert. For example, consider the alternatives described in Table 2. Let the set of alternatives be $\mathbf{S}=\{x, y, z, z z\}$. As Table 2 illustrates, there is no ranking of this set which satisfies both Priority for the More Deserving and Well-Being Pareto Indifference. But now consider a different set, namely $\mathbf{S}^{+}=\{x, y, z\}$. There $i$ a ranking of $\mathbf{S}^{+}$that satisfies both axioms. $^{48}$

Thus we might preserve the full force of the well-being Pareto principles, and apply Priority for the More Deserving only in sets of alternatives where no conflict with those principles arises. For example, we might follow this rule: if the set $\mathbf{S}$ is such that the desertmodulated continuous prioritarian formula, $\sum f\left(w_{i}, d_{i}\right)$, does not conflict with the well-being Pareto principles, use $\sum f\left(w_{i}, d_{\mathrm{i}}\right)$ to rank the alternatives in $\mathbf{S}$; otherwise, use the ordinary continuous-prioritarian formula, $\sum g\left(w_{i}\right)$, to rank $\mathbf{S}$.

Yet, as a pragmatic matter, this seems quite difficult. With a large set of alternatives, how are we to tell in advance whether the set is such that Priority for the More Deserving conflicts with the well-being Pareto principles?

A yet deeper objection to this strategy is that it violates the axiom of Consistency. Assume that two alternatives $x$ and $y$ are as described by Priority for the More Deserving-so that the axiom requires $y$ to be ranked more just than $x$. The strategy now under discussion has the upshot that $y$ is more just than $x$ if and only if the further alternatives being considered as a matter of justice meet certain conditions. ${ }^{49}$ But shouldn't the justice comparison of $x$ versus $y$ depend only on what each person's well-being and desert would be if $x$ were to obtain, and what her well-being and desert would be if $y$ were to obtain? These facts about $x$ and $y$ themselves, not the further alternatives, are sufficient to fix the ranking of $x$ versus $y$ in each person-centered ranking and the comparative strength of individual claims. That further alternatives are up for consideration is irrelevant to the pattern of claims between $x$ and $y$, and thus should be irrelevant to the justice comparison between these two.

\section{B. A Different Currency?}

The well-being Pareto principles have force, as a constraint on the justice ranking, only in virtue of the generalized Pareto principles, plus the posit that comparisons-from-a-standpoint for purposes of justice reduce to well-being comparisons. If well-being is dropped as the currency for justice, the well-being Pareto principles should also be dropped.

\footnotetext{
${ }^{48}$ Namely, $x$ and $z$ are equally just, while $y$ is more just than both.

${ }^{49}$ Namely, $y$ is more just than $x$ iff the further alternatives $z, z z, \ldots$ are such that the set comprised of these alternatives, together with $x$ and $y$, can be ranked consistently with both Priority for the More Deserving and the well-being Pareto principles.
} 
Indeed, as mentioned earlier, the appropriateness of well-being as the currency for justice is hotly contested in the literature. Other candidate currencies include resources, capabilities, "advantage," or the satisfaction of all-things-considered preferences. For short, call the new currency "justfare." We will now endorse the justfare Pareto principles (the result of combining the generalized Pareto principles with this new currency): (a) Justfare Pareto Indifference (if each person has the same level of justfare with $x$ as with $y$, the two alternatives are equally just); and (b) Justfare Strong Pareto (if at least one person has more justfare with $y$ than $x$, and everyone else has at least as much justfare with $y$, then $y$ is more just).

Yet the shift from well-being to justfare hardly salvages the project of desert-modulated claims. Suppose that individual desert is taken as an ingredient in claim strength, apart from an individual's level of justfare. This yields Priority for the More Deserving*, with the asterisk indicating that the principle is framed now in terms of justfare rather than well-being. But now Priority for the More Deserving* will come into conflict with the justfare Pareto principles, in a manner isomorphic to the conflict between Priority for the More Deserving and the well-being Pareto principles - as can be seen by variants of Tables 2 through 4 substituting justfare for wellbeing.

Perhaps, however, the thought of salvaging the project by shifting currency is meant to be taken in a different way. "Let's not use desert as an extra factor that bears on claim strength, above and beyond individual holdings of some currency. Rather, let's incorporate desert into the currency itself." Or so the thought goes.

In particular, imagine that the currency for justice is a hybrid of well-being and desert. Whether $x$ is ranked more highly than $y$ from the standpoint of $i$ depends both on how well-off individual $i$ is with each alternative, and on how deserving she is with each. This posit of a hybrid currency, if sound, would warrant desert-modulated Pareto principles (principles framed in terms of a mixture of desert and well-being), and could explain the violation of the ordinary, well-being Pareto principles with intrapersonally variable desert observed in Part V.

But this incorporationist strategy turns out be problematic. Consider two possibilities. (1) Desert and well-being are both positive contributors to the hybrid currency. If $x$ and $y$ are such that individual $i$ is equally well off with the two alternatives but has a higher desert level with $y, y$ is higher in $i$ 's person-centered ranking. Conversely, if $x$ and $y$ are such that individual $i$ is equally deserving with the two alternatives but has a higher well-being level with $y, y$ is higher in $i$ 's person-centered ranking.

A moment's reflection shows why this variant of the incorporationist strategy misfires. Imagine that Desi and Lesi are equally well off, and Desi has a higher desert level than Lesi. Thus (given the premise that desert makes a positive contribution to currency level) Desi has more of the hybrid currency than Lesi. Imagine, now, that we can increase Desi's holdings of the hybrid currency by $\Delta h$, or increase Lesi's holdings of the hybrid currency by the same 
amount, $\Delta h$. Because Desi has more of the hybrid currency, she has a weaker claim to the increase than Lesi! In short, this variant of the incorporationist strategy implies a principle of Priority for the Less Deserving! Such a principle is very counterintuitive.

The other possibility is that: (2) Desert is a negative contributor to the hybrid currency, while well-being is a positive contributor. If $x$ and $y$ are such that individual $i$ is equally well off with the two alternatives but has a higher desert level with $y, y$ is lower in $i$ 's person-centered ranking. Conversely, if $x$ and $y$ are such that individual $i$ is equally deserving with the two alternatives but has a higher well-being level with $y, y$ is higher in $i$ 's person-centered ranking.

Desert, on this approach, is like a cloudy day. If two alternatives are identical except that the first is sunny in my vicinity, while the second is cloudy, the second is worse from my perspective.

But "desert" in this negative-contribution sense is definitively not the attribute of being more deserving as discussed by the existing philosophical literature on desert - whether Arneson's work on desert and justice, or the much larger literature on desert and morality outside of justice. Consider the standard view that the morally virtuous are more deserving. ${ }^{50}$ Are things worse from my perspective, ceteris paribus, if I'm more morally virtuous? That seems wrong: either my moral virtue is a positive contributor to the quality of my life ${ }^{51}$, or it's neutral.

In the context of justice, specifically, there's some plausibility to the thought that more prudent individuals have stronger claims as a matter of justice. ${ }^{52}$ But prudence, surely, is not like a cloudy day. Prudence has a causal connection to increased well-being: the prudent individual makes choices that are apt to advance her interests. Do we want to say, now, that prudence is constitutively associated with a lower currency level: that if I am more prudent, things are (ceteris paribus) going worse from my perspective for purposes of justice? That seems absurd.

Thus the negative-contribution variant of the hybrid currency view requires a dramatic shift in the meaning of "desert" away from current usage. Moreover, the negative-contribution proposal has the troubling implication that it is pro tanto morally better, as a matter of justice, to make individuals less deserving. If individual $i$ is less deserving with $x$ than $y$, then (on the negative contribution view) $x$ is higher in $i$ 's person-centered ranking; and strong Pareto formulated in terms of the hybrid currency favors $x$ over $y$ if no one else is affected. But surely morality (in general, or in its justice component) doesn't counsel a lowering of desert. Intuition says just the opposite. For example, Arneson writes: "[I]t is better from the moral point of view that persons be more deserving rather than less deserving. At the very least, surely it is the case

\footnotetext{
50 Thomas Hurka, "Desert: Individualistic and Holistic," in Desert and Justice, 45-46; Shelly Kagan, The Geometry of Desert (New York: Oxford University Press, 2012), 5-7

${ }^{51}$ Thomas Hurka, "Objective Goods," in The Oxford Handbook of Well-Being and Public Policy, ed. Matthew D. Adler and Marc Fleurbaey (New York: Oxford University Press, 2016), 379-402.

52 See above, Part IV.
} 
that, other things being equal, it is better that a given population at a given well-being level should be more deserving rather than less deserving."

\section{Conclusion}

I conclude that the project of desert-modulated claims is unworkable. I have argued that it is implausible to see desert as internal to the currency of justice: the fact that Felicia's desert level is higher with alternative $x$ as opposed to $y$ does not, as such, change the comparative position of the two alternatives in Felicia's person-centered ranking. If desert is external to the currency of justice, then someone's desert figures in the strength of her claim between two alternatives by functioning as a strength-relevant factor in addition to her currency levels in the two. But, with intrapersonally variable desert, the posit of desert as a non-currency determinant of claim strength can conflict with the generalized Pareto principles.

More specifically, anyone who believes that well-being is the currency of justice - that comparisons-from-a-standpoint are a matter of goodness-for the individual (her welfare) should embrace the well-being Pareto principles as a matter of justice, and should reject the supposition that more deserving individuals have stronger claims.

I believe that the claims framework is a fruitful way to flesh out the more basic idea that justice is grounded in the separateness of persons. The reader may disagree; and if so she may not care much about the prospect for desert being linked to claims. But the lessons here transcend the framework. The principle of Priority for the More Deserving is a very intuitive one, quite apart from any notion of claims. The analysis here shows that Priority for the More Deserving cannot be endorsed on pain of conflict with the well-being Pareto principles; and more generally that Priority for the More Deserving reformulated in some non-well-being currency cannot be endorsed on pain of conflict with the Pareto principles in terms of that currency.

From another direction, it might be objected that the conflict between Priority for the More Deserving and the Pareto principles is obvious. Indeed, the social choice literature has already documented various conflicts between non-welfare moral considerations and the Pareto principles. ${ }^{54}$ But, I believe, the new conflict described here is actually pretty subtle. It arises only with intrapersonally variable desert. With intrapersonally fixed desert, the desertmodulated continuous prioritarian formula $\sum f\left(w_{i}, d_{\mathrm{i}}\right)$ is a generalization of standard prioritarianism that both satisfies the well-being Pareto principles and satisfies Priority for the More Deserving - thus giving weight to desert quite apart from well-being.

\footnotetext{
53 "Desert and Equality," 286.

${ }^{54}$ See, e.g., Amartya Sen, "The Impossibility of a Paretian Liberal,” Journal of Political Economy 78 (1970): 15257; Kaplow and Shavell, "Any Non-welfarist Method of Policy Assessment Violates the Pareto Principle"; Marc Fleurbaey and Alain Trannoy, "The Impossibility of a Paretian Egalitarian," Social Choice and Welfare 21 (2003): 243-63; Louis Kaplow and Steven Shavell, Fairness versus Welfare (2002).
} 
The analysis here confirms Rawls' position that desert is irrelevant to justice ${ }^{55}$ (although for reasons quite different from Rawls'). Conversely, nothing here undercuts the potential moral relevance of desert apart from justice — as in Shelly Kagan's recent work. Kagan comprehensively elaborates a view of desert's moral relevance which embraces the premise that each person's desert basis fixes for her an optimum, "peak," level of well-being, and that there is moral value in reducing someone's well-being, if her welfare is above this peak. ${ }^{56}$ Kagan does not propose that justice favors a reduction in above-peak well-being. Indeed, a viable conception of justice will surely not incorporate a person-specific peak, above which well-being reductions improve justice. Such a view of justice is obviously inconsistent with a well-being currency; nor do I see how it can be reconciled with any other plausible currency. But Kagan's work could well be a persuasive account of some impersonal component of morality

Finally, what are the lessons here for luck egalitarianism? Luck egalitarianism, of course, is about justice. The claim is that we should take account not merely of well-being, but also of some non-welfare consideration - specifically, a consideration such as individual control, choice, responsibility, fault or desert - in determining what justice requires. The analysis here shows, first, that desert is not the appropriate such consideration. More generally, it shows that the luck egalitarian needs to be careful that her conception of justice does not incorporate her chosen non-welfare consideration in a manner that violates the generalized Pareto principles. Can the luck egalitarian successfully accomplish this? One plausible approach, perhaps, is to see opportunity for well-being (rather than straight well-being) as the currency for justice - so that individuals' claims are valenced in terms of their opportunities (not well-being); and the Pareto principles are endorsed in a form that says, two alternatives yielding the very same opportunities for each person are equally just, and an increase in at least one person's opportunities with a reduction in no one's is an improvement with respect to justice. ${ }^{57}$ Exploring this variation of the claims framework must, however, be left for another day.

\section{Appendix}

\section{A. $\quad$ Priority for the More Deserving}

Let $\mathbf{S}$ include alternatives $x, y, z$, and $z z$ as described in the table immediately below. Then there is no transitive ranking of $\mathbf{S}$ that satisfies Priority for the More Deserving without proviso (5). Note that this axiom requires that $y$ be ranked more just than $x, z$ more just than $y, z z$ more just than $z$, and $x$ more just than $z z$.

\footnotetext{
${ }^{55}$ John Rawls, A Theory of Justice (Cambridge: Harvard University Press, 1972), 311.

${ }^{56}$ The Geometry of Desert, 180; see also Hurka, "Desert: Individualistic and Holistic," 46.

${ }^{57}$ Construing opportunity for well-being as the currency of justice seems to fit well with what Francisco Ferreira and Vito Peragine term the "ex ante" approach in their recent review of the economic literature on equality of opportunity. "Individual Responsibility and Equality of Opportunity," in The Oxford Handbook of Well-Being and Public Policy, 746-84.
} 


\section{Appendix Table 1}

$\begin{array}{lllll} & \underline{\text { Alt. } x} & \underline{\text { Alt. }} & \underline{\text { Alt. } z} & \underline{\text { Alt zz }} \\ \text { Able } & \mathrm{W} \mathrm{D}^{+} & \mathrm{W} * \mathrm{D}^{+} & \mathrm{W}^{* *} \mathrm{D}^{+} & \mathrm{W}^{* *} \mathrm{D}^{+} \\ \text {Baker } & \mathrm{W}^{*} \mathrm{D} & \mathrm{W} \mathrm{D} & \mathrm{W} \quad \mathrm{D}^{+++} & \mathrm{W}^{*} \mathrm{D}^{+++} \\ \text {Charlie } & \mathrm{W}^{* *} \mathrm{D}^{++} & \mathrm{W} * * \mathrm{D} & \mathrm{W} * \mathrm{D} & \mathrm{W} \mathrm{D}^{++}\end{array}$

Explanation: $\mathrm{W}, \mathrm{W}^{*}, \mathrm{~W}^{* *}$ are well-being bases, such that someone with $\mathrm{W}^{* *}$ is better off than someone with $\mathrm{W}^{*}$, in turn better off than someone with $\mathrm{W} . \mathrm{D}, \mathrm{D}^{+}, \mathrm{D}^{++}, \mathrm{D}^{+++}$are desert bases, such that someone with $\mathrm{D}$ is less deserving than someone with $\mathrm{D}^{+}$, who is less deserving than someone with $\mathrm{D}^{++}$, who is less deserving than someone with $\mathrm{D}^{+++}$.

\section{B. Continuous Prioritarianism}

The justice ranking of any given set $\mathbf{S}$ of alternatives is a quasiordering, which I abbreviate as $\geqslant \mathbf{S}$. " $x \geqslant \mathbf{S} y$ " indicates that $x$ is at least as just as $y$ according to the justice ranking of $\mathbf{S}$.

I provide a sketch of the proof that, under appropriate axiomatic assumptions, $\geqslant \mathbf{S}$ can be represented by the continuous-prioritarian formula. That is:

$$
x \geqslant \mathrm{~S} y \text { iff } \sum_{i=1}^{N} g\left(w_{i}^{x}\right) \geq \sum_{i=1}^{N} g\left(w_{i}^{y}\right)
$$

for some strictly increasing and concave function $g($.$) .$

I assume that every $\mathbf{S}$ at issue is a subset of a grand set of alternatives $\mathbf{O}$, and that $\geqslant$ satisfies the well-being Pareto principles, Pigou Dalton, Anonymity, Separability, and Completeness. (The other axioms mentioned in the text, namely Measurability, Continuity and Consistency will be introduced momentarily.). Individual desert levels are the same intra- and interpersonally in $\mathbf{O}$ (and thus every $\mathbf{S}$ ).

I also assume that $N \geq 3$.

By Measurability, there is a well-being measure $w($.$) such that individual i$ with alternative $x$ is at least as well off as individual $j$ with alternative $y$ iff $w_{i}^{x} \geq w_{j}^{y}$, for any two alternatives $x, y$ (distinct or identical) and any two individuals $i, j$ (distinct or identical). Further, the difference between the well-being of individual $i$ with $x$ and individual $j$ with $y$ is at least as large as the difference between the well-being of individual $k$ with $z$ and individual $l$ with $z z$ iff $w_{i}^{x}-w_{j}^{y} \geq w_{k}^{z}-w_{l}^{z z}$ (the individuals and alternatives distinct or identical).

Consider first the justice ranking of $\mathbf{O}$. Let $\mathbf{v}(x)$ be the vector of well-being numbers associated with $x$, i.e., $\mathbf{v}(x)=\left(w_{1}^{x}, \ldots, w_{N}^{x}\right)$, and let $\mathbf{V}$ be the set of well-being vectors 
corresponding to $\mathbf{O}$, i.e., $\mathbf{v}(x) \in \mathbf{V}$ iff $x \in \mathbf{O}$. For any well-being vector $\mathbf{v} \in \mathbf{V}$, arbitrarily choose some $x \in \mathbf{O}$ s.t. $\mathbf{v}(x)=\mathbf{v}$, and denote this alternative as $a^{-1}(\mathbf{v})$. Then define a quasiordering $\geqslant \mathbf{v}$ of $\mathbf{V}$ as follows: $\mathbf{v} \geqslant \mathbf{v} \mathbf{v}^{*}$ iff $a^{-1}(\mathbf{v}) \geqslant \mathbf{0} a^{-1}\left(\mathbf{v}^{*}\right)$.

Note that, because $\geqslant \mathbf{0}$ satisfies well-being Pareto indifference, $\geqslant \mathbf{v}$ is the same regardless of which $x$ in $\mathbf{O}$ is chosen as $a^{-1}(\mathbf{v})$, if there is more than one $x$ with $\mathbf{v}$ as its well-being vector. Conversely:

(2) $x \geqslant \mathbf{0} y$ iff $\mathbf{v}(x) \geqslant \mathbf{v} \mathbf{v}(y)$.

Because $\geqslant^{0}$ satisfies Separability, $\geqslant \mathbf{v}$ satisfies a corresponding separability axiom defined in terms of well-being vectors. ${ }^{58}$ Moreover, because $\succcurlyeq^{\mathbf{0}}$ satisfies Completeness, $\geqslant \mathbf{V}$ is complete.

Let's add a "richness" axiom. There is some single nondegenerate interval $I$ of real numbers $[a, b],(a, b),[a, b),(a, b]$, with $a<b$, or $(-\infty, a],(-\infty, a),[a, \infty),(a, \infty)$, or $(\infty, \infty)$, such that $\mathbf{V}$ is the $N$-fold Cartesian product of this interval. Assume, finally, that $\geqslant \mathbf{V}$ satisfies Continuity.

An established result in utility theory is that a separable, complete, and continuous quasiordering of a product space of at least three connected metric spaces has a continuous additive representation. ${ }^{59}$ Thus there exist continuous functions $g_{1}(),. g_{2}(),. \ldots, g_{\mathrm{N}}($.$) such that:$

(3) $\mathbf{v}(x) \geqslant \mathbf{v} \mathbf{v}(y)$ iff $\sum_{i=1}^{N} g_{i}\left(w_{i}^{x}\right) \geq \sum_{i=1}^{N} g_{i}\left(w_{i}^{y}\right)$

Because $\succcurlyeq^{\mathbf{0}}$ satisfies Anonymity, there exists a single $g(.)^{60}$ such that:

\footnotetext{
${ }^{58}$ Let $\mathbf{v}, \mathbf{v}^{*}, \mathbf{v}^{+}, \mathbf{v}^{++}$be any four well-being vectors such that, for every $i$ in some subset of the population, the $i$ th entry of $\mathbf{v}$ is equal to the $i$ th entry of $\mathbf{v}^{*}$, and the $i$ th entry of $\mathbf{v}^{+}$is equal to the $i$ th entry of $\mathbf{v}^{++}$. Further, for every $j$ not in this subset, the $j$ th entry of $\mathbf{v}^{+}$equals the $j$ th entry of $\mathbf{v}$ and the $j$ th entry of $\mathbf{v}^{++}$equals the $j$ th entry of $\mathbf{v}^{*}$. Then separability with respect to well-being vectors requires that: $\mathbf{v} \geqslant \mathbf{v} \mathbf{v}^{*}$ iff $\mathbf{v}^{+} \geqslant^{\mathbf{v}} \mathbf{v}^{++}$.

${ }^{59}$ See Peter Wakker, "The Additive versus the Topological Approach to Additive Representations," Journal of Mathematical Psychology 32 (1988): 421-435. Connectedness is satisfied because $I$ is an interval. It's also required that the quasiordering be sensitive to changes in at least three of the spaces ("essentiality"), which is satisfied here because $I$ is nondegenerate and $\succcurlyeq^{0}$ satisfies Well-Being Strong Pareto.

${ }^{60}$ Because $\geqslant^{\mathbf{O}}$ satisfies Anonymity, $\geqslant \mathbf{v}$ satisfies a corresponding anonymity axiom ("Permutation"): if $\pi($.) is a permutation mapping on the set of individuals, and $\mathbf{v}$ and $\mathbf{v}^{*}$ are such that the $i$ th entry of $\mathbf{v}$ is equal to the $\pi(i)$ th entry of $\mathbf{v}^{*}$ for every $i$, then $\mathbf{v} \sim^{\mathbf{v}} \mathbf{v}^{*}$. Now consider $g_{1}($.$) and g_{i}($.$) in equation (3). By virtue of Permutation, g_{i}($.$) is$ just $g_{1}($.$) plus some constant c_{i}$ : for every $w, g_{i}(w)=g_{1}(w)+c_{i}$. To see why, arbitrarily pick some $w^{+}$and for any $w$, pick vectors $\mathbf{v}$ and $\mathbf{v}^{*}$ which are identical except that the first entry of $\mathbf{v}$ is $w^{+}$and the $i$ th entry is $w$, while the first entry of $\mathbf{v}^{*}$ is $w$ and the $i$ th entry is $w^{+}$. By Permutation, $g_{1}\left(w^{+}\right)+g_{i}(w)=g_{1}(w)+g_{i}\left(w^{+}\right)$. Thus for any $w, g_{i}(w)=$ $g_{1}(w)+c_{\mathrm{i}}$, with $c_{\mathrm{i}}=g_{i}\left(w^{+}\right)-g_{1}\left(w^{+}\right)$.

Substituting $g_{1}()+.c_{i}$ for $g_{i}($.$) in equation (3), and subtracting the sum of c_{i}$ from each side, we have that $\mathbf{v}(x) \geqslant \mathbf{v} \mathbf{v}(y)$ iff $\sum_{i=1}^{N} g_{1}\left(w_{i}^{x}\right) \geq \sum_{i=1}^{N} g_{1}\left(w_{i}^{y}\right)$. Now define $g()=.g_{1}($.$) , and we have (4).$
} 
(4) $\mathbf{v}(x) \geqslant \mathbf{v} \mathbf{v}(y)$ iff $\sum_{i=1}^{N} g\left(w_{i}^{x}\right) \geq \sum_{i=1}^{N} g\left(w_{i}^{y}\right)$

Because $\succcurlyeq^{\mathbf{O}}$ satisfies Well-Being Strong Pareto, $g($.$) must be strictly increasing; { }^{61}$ and because $\succcurlyeq^{0}$ satisfies Pigou-Dalton, $g\left(\right.$.) must be strictly concave. ${ }^{62}$

Consider now the justice ranking of any $\mathbf{S} \subseteq \mathbf{O}$. By Consistency,

(5) $x \geqslant \mathbf{S} y$ iff $x \geqslant \mathbf{0} y$.

Putting together (5), (4), and (2), we arrive at (1).

\section{Desert-Modulated Continuous Prioritarianism}

I now sketch a proof that, under appropriate axiomatic conditions, $\succcurlyeq \mathbf{S}$ can be represented by the desert-modulated continuous-prioritarian formula. That is:

$$
\left(1^{*}\right) x \geqslant \mathrm{~S} y \text { iff } \sum_{i=1}^{N} f\left(w_{i}^{x}, d_{i}^{x}\right) \geq \sum_{i=1}^{N} f\left(w_{i}^{y}, d_{i}^{y}\right)
$$

for some $f($.$) that is strictly increasing and concave in w$ and satisfies the "slope condition" (below).

As above, every $\mathbf{S}$ at issue is a subset of a grand set of alternatives $\mathbf{O}$. I also assume that $\geqslant$ satisfies DM Anonymity, DM Separability, and Completeness. Finally, $N \geq 3$.

Assume DM Measurability, namely that Measurability (above) holds true and also: there is a desert measure $d($.) such that individual $i$ with alternative $x$ is at least as deserving as individual $j$ with alternative $y$ iff $d_{i}^{x} \geq d_{j}^{y}$, for any two alternatives and individuals, distinct or identical.

Let $\mathbf{v}(x)$ now denote the vector of well-being and desert numbers associated with $x$, i.e., $\mathbf{v}(x)=\left(\left(w_{1}^{x}, d_{1}^{x}\right), \ldots,\left(w_{N}^{x}, d_{N}^{x}\right)\right) . \mathbf{V}$ is the set of such well-being/desert vectors. For any $\mathbf{v} \in \mathbf{V}$ arbitrarily choose some $x \in \mathbf{O}$ s.t. $\mathbf{v}(x)=\mathbf{v}$, and denote this alternative as $a^{-1}(\mathbf{v})$. Then define a quasiordering $\geqslant \mathbf{v}$ of $\mathbf{V}$ as follows: $\mathbf{v} \geqslant \mathbf{v} \mathbf{v}^{*}$ iff $a^{-1}(\mathbf{v}) \geqslant \mathbf{0} a^{-1}\left(\mathbf{v}^{*}\right)$. By DM Anonymity, $\geqslant^{\mathbf{v}}$ is the same regardless of which $x$ in $\mathbf{O}$ is chosen as $a^{-1}(\mathbf{v})$. Conversely

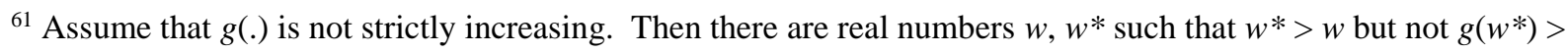
$g(w)$. Pick $x, y$ s.t. $w_{k}^{x}=w^{*}$ and $w_{k}^{y}=w$ for some $k$, with $w_{j}^{x}=w_{j}^{y}$ for $j \neq k$. Then it is not the case that $\sum_{i=1}^{N} g\left(w_{i}^{x}\right)>\sum_{i=1}^{N} g\left(w_{i}^{y}\right)$. Thus, by (2) it is not the case that $x>^{0} y$. But note that, by Measurability, $x$ and $y$ must be such that $k$ is better off with $x$ than $y$, while everyone else is equally well off. Thus we have a contradiction of Well-Being Strong Pareto, which requires that $x>^{\mathbf{0}} y$.

${ }^{62}$ If a function is continuous and strictly midconcave, it is strictly concave. Constantin Niculescu and Lars-Erik Persson, Convex Functions and their Applications: A Contemporary Approach (New York: Springer, 2006$), 10$. The function $g($.$) is continuous and, by Pigou-Dalton, strictly midconcave, hence strictly concave.$
} 
$\left(2^{*}\right) x \geqslant \mathbf{0} y$ iff $\mathbf{v}(x) \geqslant \mathbf{v} \mathbf{v}(y)$.

Because $\geqslant^{\mathbf{0}}$ satisfies DM Separability, $\geqslant^{\mathbf{V}}$ satisfies a corresponding separability axiom in terms of well-being/desert vectors ${ }^{63}$. Add a richness axiom: There is some rectangle $R$ of real numbers, consisting of the product of a non-degenerate interval of real numbers $I$ (as above) and a (possibly degenerate) interval $D$, such that $\mathbf{V}$ is the $N$-fold Cartesian product of $R$. Finally, assume $\geqslant^{\mathbf{V}}$ satisfies DM Continuity. It follows that $\geqslant^{\mathbf{V}}$ has a continuous additive representation ${ }^{64}$, namely:

$\left(3^{*}\right) \mathbf{v}(x) \geqslant \mathbf{v} \mathbf{v}(y)$ iff $\sum_{i=1}^{N} f_{i}\left(w_{i}^{x}, d_{i}^{x}\right) \geq \sum_{i=1}^{N} f_{i}\left(w_{i}^{y}, d_{i}^{y}\right)$.

Because $\succcurlyeq^{0}$ satisfies DM Anonymity ${ }^{65}$, there exists a single $f($.$) such that:$

$\left(4^{*}\right) \mathbf{v}(x) \geqslant \mathbf{v} \mathbf{v}(y)$ iff $\sum_{i=1}^{N} f\left(w_{i}^{x}, d_{i}^{x}\right) \geq \sum_{i=1}^{N} f\left(w_{i}^{y}, d_{i}^{y}\right)$

By Consistency, $\left(1^{*}\right)$ holds true for any $\mathbf{S} \subseteq \mathbf{O}$.

We now require that the well-being Pareto principles, DM Pigou-Dalton, and Priority for the More Deserving hold true for any $\mathbf{S}$ in which desert is intrapersonally fixed. If this is true then, first, by Well-Being Strong Pareto, $f($.$) must be strictly increasing in w$ : If $w^{*}>w$, then, for all $d, f\left(w^{*}, d\right)>f(w, d)$.

Second, by Priority for the More Deserving, $f($.$) must satisfy the "slope condition": If d^{*}$ $>d$, then for all $w$ and for all $\Delta w>0, f\left(w+\Delta w, d^{*}\right)-f\left(w, d^{*}\right)>f(w+\Delta w, d)-f(w, d)$.

Third, DM Pigou-Dalton imposes the additional requirement that $f($.$) be strictly concave$ in $w$. Why? By DM Pigou-Dalton, if $w^{*}>w, d^{*} \geq d$, and $0<\Delta w \leq\left(w^{*}-w\right) / 2$, then: $f\left(w^{*}, d\right)-$ $f\left(w^{*}-\Delta w, d\right)<f\left(w+\Delta w, d^{*}\right)-f\left(w, d^{*}\right)$. Consider first the case where $d^{*}=d$. For DM PigouDalton to be satisfied in that case, the $f\left(\right.$.) function must be strictly concave in $w .{ }^{66}$ Adding the slope condition ensures that, if $f($.$) is strictly concave in w$, DM Pigou-Dalton is satisfied with $d^{*}$ $>d$.

${ }^{63}$ Let $\mathbf{v}, \mathbf{v}^{*}, \mathbf{v}^{+}, \mathbf{v}^{++}$be four well-being/desert vectors such that, for every $i$ in some subset of the population, individual $i$ 's well-being and desert number in $\mathbf{v}$ are equal, respectively, to her well-being and desert number in $\mathbf{v}^{*}$; and her well-being and desert number in $\mathbf{v}^{+}$are equal, respectively, to her well-being and desert number in $\mathbf{v}^{++}$. Further, for every $j$ not in this subset, $j$ 's well-being and desert number in $\mathbf{v}$ are equal, respectively, to her well-being and desert number in $\mathbf{v}^{+}$; and her well-being and desert number in $\mathbf{v}^{*}$ are equal, respectively, to her well-being and desert number in $\mathbf{v}^{++}$. Then separability with respect to well-being/desert vectors requires that: $\mathbf{v} \geqslant \mathbf{V} \mathbf{v}^{*}$ iff $\mathbf{v}^{+} \geqslant \mathbf{v} \mathbf{v}^{++}$. ${ }^{64} \mathrm{By}$ the same results in utility theory cited above note 59. The assumption that $I$ is nondegenerate together with Well-Being Strong Pareto in any $\mathbf{S}$ with desert intrapersonally fixed is sufficient to satisfy "essentiality," even if $D$ is a single value (a degenerate interval).

${ }^{65}$ This induces a corresponding axiom on $\geqslant \mathbf{v}$. Let $\pi($.) be any permutation mapping on the set of individuals. Let $\mathbf{v}$ and $\mathbf{v}^{*}$ be such that, for every $i$, individual $i$ 's well-being and desert number in $\mathbf{v}$ are equal, respectively, to the wellbeing and desert number in $\mathbf{v}^{*}$ of $\pi(i)$. Then $\mathbf{v} \sim \sim^{\mathbf{v}} \mathbf{v}^{*}$. The proof of (4*) then parallels the steps in note 60 above. ${ }^{66}$ By the results regarding strict midconcavity mentioned above note 62 . 
Note that $f($.$) being strictly increasing and concave and satisfying the slope condition is$ not only necessary but sufficient to ensure that the well-being Pareto principles, DM PigouDalton, and Priority for the More Deserving hold true for any $\mathbf{S}$ in which desert is intrapersonally fixed. (By contrast, as observed in the main text, equation $\left(1^{*}\right)$ does not necessarily satisfy the well-being Pareto principles if desert is intrapersonally variable in $\mathbf{S}$. Nor, it should be noted, does it necessarily satisfy DM Pigou-Dalton.)

It would be interesting to provide a more detailed mathematical characterization of the family of $f($. $)$ functions. One simple subfamily within this family is as follows: $f(w, d)=g(w) \times$ $h(d)$, with $g($.$) a strictly increasing and concave function, and h($.$) a strictly increasing (and$ positively valued) function. 